BIA2.0:

\title{
ADVANCING THE ROLE OF BUSINESS IMPROVEMENT AREAS IN COMMUNITY PLANNING
}

\author{
by \\ Sarah Lesley Millar \\ BA (Honours) Geography (Urban Development), Western University, 2003
}

\author{
A Major Research Paper \\ presented to Ryerson University \\ in partial fulfillment of the requirements for the degree of \\ Master of Planning \\ in \\ Urban Development
}

Toronto, Ontario, Canada 2015

(C) Sarah Millar, 2015 


\section{AUTHORS DECLARATION}

I hereby declare that I am the sole author of this MRP. This is a true copy of the MRP, including any required final revisions.

I authorize Ryerson University to lend this MRP to other institutions or individuals for the purpose of scholarly research.

I further authorize Ryerson University to reproduce this MRP by photocopying or by other means, in total or in part, at the request of other institutions or individuals for the purpose of scholarly research.

I understand that my MRP may be made electronically available to the public. 
BIA2.0:

\section{ADVANCING THE ROLE OF BUSINESS IMPROVEMENT AREAS IN COMMUNITY PLANNING}

(C) Sarah Millar, 2015

\section{Master of Planning}

in

Urban Development

Ryerson University

\section{ABSTRACT}

This paper specifically looks at the role Business Improvement Areas (BIAs) fulfill in both urban and rural contexts in order to characterize a perceived trend toward broad based community planning and local economic development work. The method draws on literature, award winning case examples, primary interview findings and an examination of planning tools to determine BIAs position within the planning framework, and advance recommendations for a BIA2.0 agenda.

The findings confirm BIAs position in community planning and local economic development work, and outlines opportunities to advance their role as community building agents as part of the BIA2.0 agenda. Ultimately, the research highlights the BIA as a unique relationship shared between municipalities and business owners. It presents a rare opportunity for planners and policy makers to harness BIAs entrepreneurial spirit, market knowledge and social capital in order to implement policy objectives from the ground up.

Key Words: Business Improvement Areas; local economic development; community planning; place making; small business; Ontario. 


\section{ACKNOWLEDGEMENTS}

The completion of this research paper marks the end of an incredible year both personally and professionally.

I would like to thank my supervisor, Dr. Pamela Robinson, for her tireless support and guidance throughout this research. I would also like to thank my second reader, Diane Ploss, for her insight and enthusiasm on the work of Business Improvement Areas in Ontario. In addition, interview participants who contributed their time and expertise were invaluable to this process.

Finally I would like to thank my family and in particular my dad, who has always encouraged me to look out the window at what Mainstreet Ontario has to offer. 


\section{GLOSSARY OF TERMS}

ABC Agencies, Boards and Commissions

BIA Business Improvement Area

BIA1.0 Existing BIA practice

BIA2.0 Potential BIA practice

CD Community Development (Economic Development \& Community Planning)

CDA Community Development Area

CIP Community Improvement Plan

COTA City of Toronto Act, 2006

DC Development Charges

DPS Development Permit System

HCD Heritage Conservation District

IMFG Institute of Municipal, Finance and Governance

LED Local Economic Development

Levy Business Improvement Area Levy

MA Municipal Act, 2001

MEDEI Ministry of Economic Development, Employment and Infrastructure

MMAH Ministry of Municipal Housing and Affairs

MTCS Ministry of Tourism, Culture and Sport

OP Official Plan

OPA Official Plan Amendment

OMAFRA Ontario Ministry of Agriculture and Rural Affairs

PPS Provincial Policy Statement

ZBL Zoning By-Law 


\section{TABLE OF CONTENTS}

1.0 INTRODUCTION

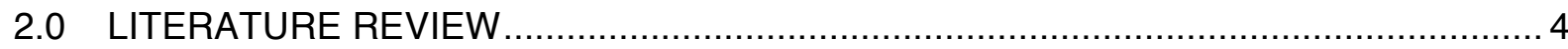

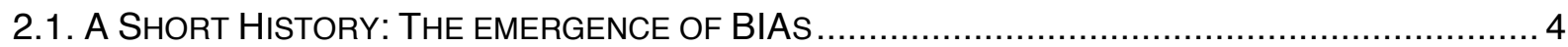

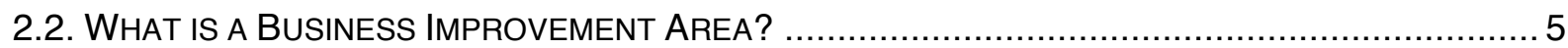

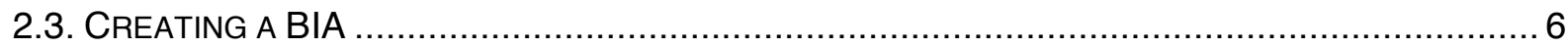

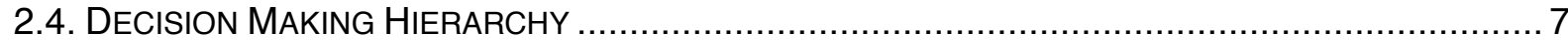

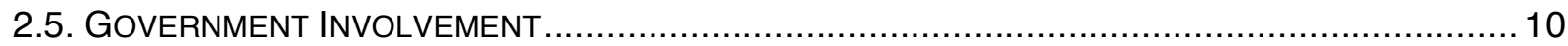

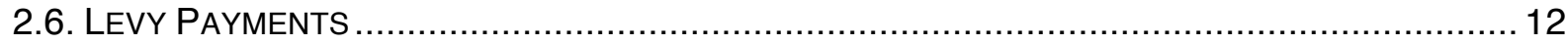

2.7. ORGANIZING BUSINESS: EXPLORING ALTERNATIVES TO THE BIA MODEL............................13

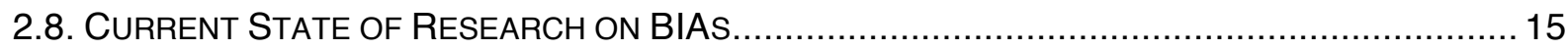

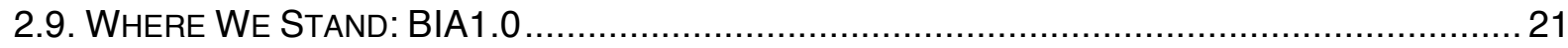

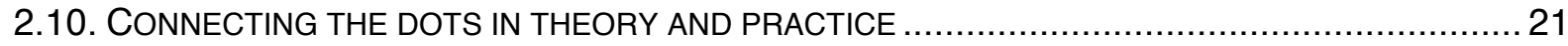

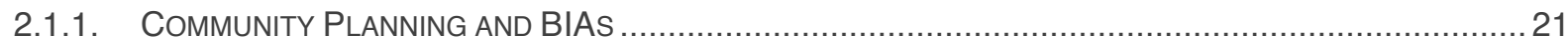

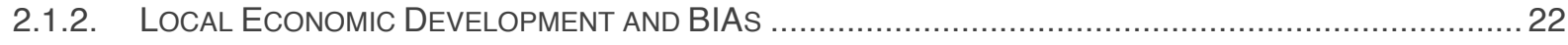

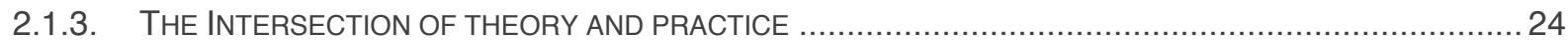

2.11. IS A NEW ROLE FOR BIAS EMERGING? READING SIGNALS FROM THE FIELD ......................2 25

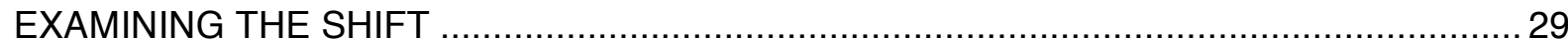

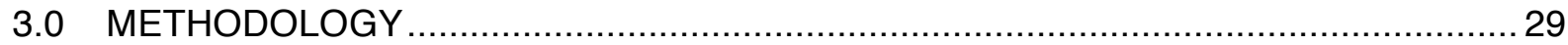

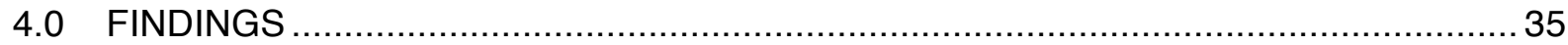

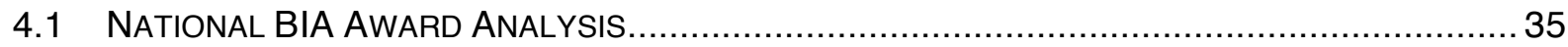

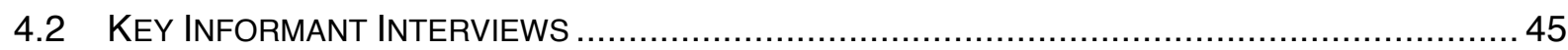

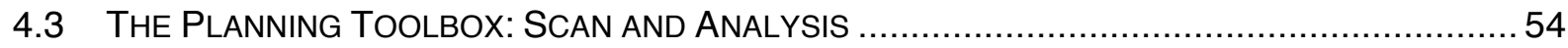

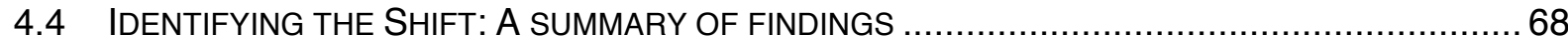

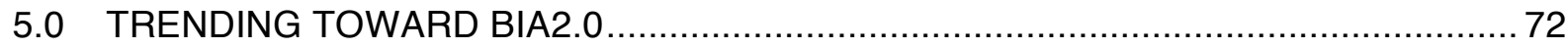

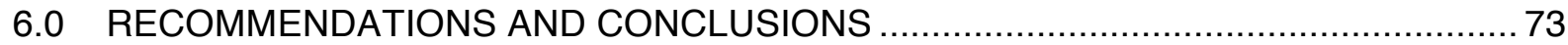

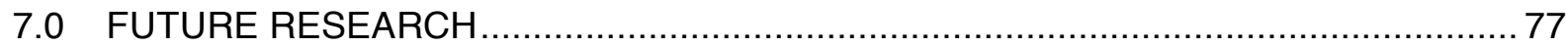

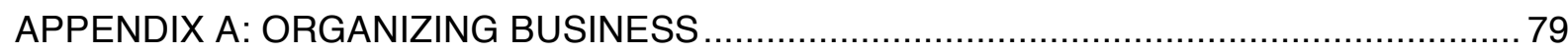

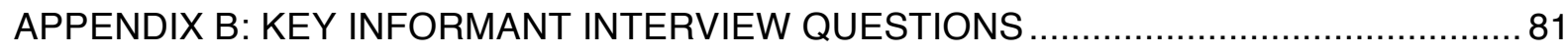

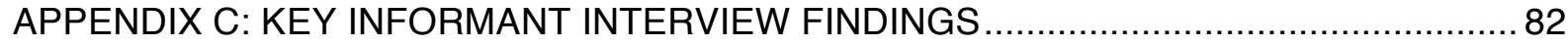

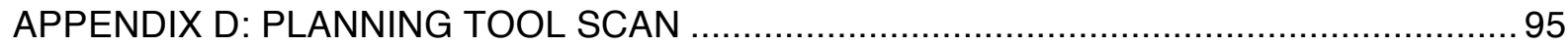

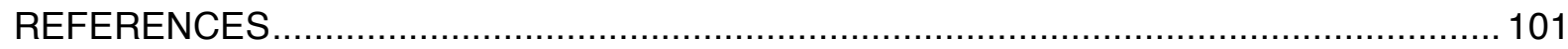




\section{FiguRe REFERENCE}

FIGURE 1: BIA DECISION MAKING HIERARCHY

FIGURE 2: GOVERNMENT CONNECTIONS

FIGURE 3: COMPARISON OF BUSINESS STRUCTURES

Figure 4: ALIGNING BIA PRACTICE WITH COMMUNITY DEVELOPMENT

FIGURE 5: AWARD ALIGNMENT IN PLANNING AND ECONOMIC DEVELOPMENT.

FIGURE 6: 2015 AWARD BREAKDOWN BY POPULATION SIZE

FIGURE 7: 2015 AWARD BREAKDOWN BY ECONOMIC REGION

FIGURE 8: 2015 AWARD BREAKDOWN BY REGION, COUNTY OR DISTRICT

FIGURE 9: 2012- 2015 AWARD BREAKDOWN BY POPULATION SIZE

FIGURE 10: 2012- 2015 AWARD BREAKDOWN BY ECONOMIC REGION

FIGURE 11: 2012- 2015 AWARD BREAKDOWN BY REGION, COUNTY OR DISTRICT

FIGURE 12: 2015 AWARD SUBMISSIONS BY CATEGORY

FIGURE 13: PLANNING TOOLS IMPACTING BIAS IN THE ONTARIO PLANNING SYSTEM

Figure 14: PlanNing ToOl Influence Matrix

Figure 15: BIA SPECTRUM OF PRACTICE 


\subsection{Introduction}

A Business Improvement Area (BIA) is a unique and legislated municipal business organization that allows for a defined geographic area of commercial significance to be designated as a special levy precinct (MMAH, 2010). Traditionally BIAs were formed around community main streets and downtown areas, representing the interest of small and medium business. Today, BIAs exist in a variety of settings - from rural mainstreets (Uxbridge BIA), to large industrial parks (Kanata North BIA), to mixed-use urban neighbourhoods (Liberty Village BIA). As a local board of the municipality, they are guided by a distinct section of provincial legislation along with an approved municipal bylaw, to promote commercial activity and enhance area beautification using a regulated municipal levy payable.

The concept of a BIA has existed since 1970. In fact, Ontario is home to the first BIA in the world, located in Bloor West Village, and implemented under provincial legislation (MMAH, 2010). The growth of BIAs since their inception in 1970 has been truly exceptional. Over the past 45 years, the number of BIAs in Toronto alone has gone from 1 to 81. According to the Ontario Business Improvement Area Association membership (2015), there are currently an estimated 305 BIAs across the province, and roughly 700 across the Canadian landscape (Rotman, 2015).

The United States, by comparison, is home to over 1,000 Business Improvement Districts (BID) (IDA, 2011). "According to the International Downtown Association (IDA) 2011 BID census report, all US states except two (North Dakota and Wyoming), including the District of Columbia, have at least one business improvement district, with an average of twenty BIDs per state" (Ha, 2011, p.vi).

On a global scale, the idea of a designated business area with its own special levy, has ballooned throughout the United Kingdom, Germany, Japan, and South Africa (Rotman, 2015). Evident through sheer growth of the concept, something is working. John Kiru, Executive Director of the Toronto Association of Business Improvement Areas (TABIA) 
often attests that BIAs are 'Canada's largest export and Ontario's most successful publicprivate partnership' (Rotman, 2015).

Despite this growth, there remains an unsettling confusion around the role that they play in cities and towns alike. Their potential to implement real change in our local community fabric ranges across the province from positive to negative. Anecdotal recognition of streetscape improvement efforts - from lamp posts to street furniture and building facades; examples of festival and event organization; and broader strategic initiatives all exemplify their positive influence. But the opposite also exists. Cases of corruption, political manoeuvring, and total disbandment have left some with the perception that BIAs do nothing to facilitate stronger communities and in fact, work against the (personal communication, 2015). The factors that influence these efforts are seemingly varied and contextual, and the potential impact on this support system for small business significant. An idea conceived through the ingenuity of small business retail owners, the BIA model appears to offer planning practioners and policy makers a window into the mechanics of neighbourhood resiliency.

This study will explore the role Business Improvement Areas are currently fulfilling in community planning and local economic development through an evaluation of theory, policy, and practice. It will then investigate how that role could be enhanced and supported through the planning framework, its policies and tools. This research will answer the question:

What role are BIAs fulfilling in community planning and economic development, and what function can planning policy and practice play in supporting their ability to deliver broader municipal objectives at a local level?

The paper is structured to progress systematically toward recommendations for advancing a next generation, BIA2.0 framework. The components of the paper are listed below. 
Context and History: An initial exploration of the historical growth of BIAs will help to lay the foundation of their existence and their importance in the local, provincial and global context. Beyond that, a scan of current legislation is provided along with an understanding of how BIAs are structured and operated.

Literature Review: A scan of existing literature on Business Improvement Areas will provide academic insight into current trends and challenges in the practice as well as a clear understanding of the breadth of academic study that exists. On completion of the literature review, a summary of BIA1.0 practice will be completed.

Connecting the Dots in Theory and Practice: This section will examine the concepts of community planning and local economic development to understand if and where linkages exist to the work of Business Improvement Areas. This analysis will look to ground overarching community development principles in BIA practice and in turn set a baseline for assessment of the role BIAs can play in this arena.

Realistic Growth: Known examples of BIA involvement in community development work will be presented to highlight signals of what appears to be an emerging trend.

Examining the Shift: Using the work completed to identify historical context and community development linkages, an analysis of industry awards and primary interview responses will then be completed. This work will inform our understanding of current trends in practice, and clearly identify what role BIAs play in local communities. Analysis of the barriers that exist in practice and a scan of planning tools currently available will set the groundwork for a comprehensive set of recommendations to advance a BIA2.0 agenda will then be provided. 


\subsection{Literature Review}

\subsection{A Short History: The emergence of BIAs}

The concept of a Business Improvement Areas (BIA) was formed in Bloor West Village in Toronto, Ontario around 1969 (MMAH, 2010). At the time, increased vacancy rates and low consumer spending were changing the appearance of and investment in neighbourhood retail spaces across the city. The development of a number of suburban shopping centres in the 1960s, most notably Yorkdale Mall, effectively pushed consumers outward, while the extension of the Bloor-Danforth Subway line, drove traditional mainstreet activity underground. This led to a growing concern amongst business owners and local entrepreneurs on their continued livelihood at stake in the face of changing urban form and retail consumer patterns (Rotman, 2015).

By 1967, Alex Ling, a local businessman in the Bloor West area joined with a number of other concerned business and property owners to approach City Hall and suggest formalizing what had been a voluntary business association through legislation (Gomez, 2015). The premise was to secure a guaranteed revenue stream for mainstreet improvements through a BIA levy, and alleviate the stress and uncertainty of voluntary contributions. It would effectively act as a membership fee to be used toward broader public realm improvements (MMAH, 2010). Their theory built on the idea that pooled social and financial resources within a commercial area could improve independent business owners opportunity to bring customers back to their local mainstreet (Gomez, 2015). They were right. The recognition of neighbouring business owners as 'allies instead of enemies' led to the push for this form of organized business structure. The district levy working to provide guaranteed revenue to allow for streetscape improvements, and in turn shift the general business mindset from independent wealth to collective benefit. The City of Toronto agreed to the proposal in Bloor West Village, and in 1970, provincial legislation was passed formally creating the Bloor West Village Business Improvement Area and associated board of management (Rotman, 2015).

A milestone achievement in the concept of public-private governance over public space, it is somewhat surprising that little attention has been paid to benefit of BIAs in this 
arena. As Gomez (2015) attests, "Considering that Toronto is the birthplace of the modern BIA concept, relatively little public attention has been paid to this uniquely Canadian invention and the history behind it” (p.36). The creation of BIAs in effect pays homage to 'Mainstreet Ontario' as an important place in local communities. The cultural, historic, and commercial significance of traditional mainstreets brings with it the need for stewardship and investment in order to move through anticipated and continuous economic cycles. The responsibility BIAs assume over these important community places will be explored in greater detail throughout this study.

\subsection{What is a Business Improvement Area?}

It is important to be clear about what a Business Improvement Area actually is who it serves and how its run. A BIA is a formal group of property and business owners who have a vested interest in commercial activity along a mainstreet or within a downtown area. Traditionally, formed around small retail businesses, BIAs today consist of a variety of commercial business types and tenants - from the service industry, to retail, entertainment, high tech, and light industrial uses. As detailed by the province, "The unifying characteristic is an interest in enhancing their business area and improving their community" (MEDEI, 2015, p.2). The term Business Improvement Area is often used to describe both the defined geographical area, and the organization of businesses and property owners within it. A testament to the link between the Board and the area they serve. In the Ontario context, BIAs are considered legislated boards of the local municipal council and regulated under the Municipal Act, 2001 sections 203-215. Section 216 and other sections of the Municipal Act goes on to outline the authority of municipalities over their local boards, of which, BIAs are a part. Section 204 (1) outlines the mandate of a BIA as follows:

A local municipality may designate an area as an improvement area and may establish a board of management,

a) to oversee the improvement, beautification and maintenance of municipally owned land, buildings and structures in the area beyond that provided at the expense of the municipality generally; and

b) to promote the area as a business or shopping area. 2001, s. 204 (1). 
The City of Toronto, having its own provincial legislation, outlines its BIA regulations under Chapter 19 of the City of Toronto Act, 2006. Both pieces of legislation establish a baseline of responsibility for BIAs to address. At their most basic function BIAs are required to manage improvements, enhancements and maintenance of publicly owned spaces and buildings above and beyond that of the municipality, and promote the commercial livelihood of the area. The extent to which these objectives being met and exceeded will be the focus of this study.

\subsection{Creating a BIA}

The creation of a Business Improvement Area and its associated board of management are guided by legislation under the Municipal Act, 2001. The establishment of a BIA may be initiated by a number of stakeholders, including: local business owners, municipal council, elected officials or staff who see the benefit of additional investment within a defined commercial area. Where its creation is warranted, commitment and leadership from local businesses and property owners and collaboration with the local municipality become essential to future operation and success (MMAH, 2010).

Once general interest in the creation of a BIA is established, approval under municipal by-law is required to formally establish the BIA Board and its geographic boundaries. Interestingly, the legislation in place has created an objection-based process for the determination of BIAs across the province. Once a BIA by-law is drafted the council states an intention on passing a by-law and then measures "buy-in" from the public. Objection by commercial property owners and tenants could result in the refusal of the by-law altogether.

Section 210 (3) outlines the determinants for refusal of a by-law to create or expand a BIA. It specifies that where an objection has been signed by at least one third of the total number of persons entitled to the initial notice of passing, and that percentage represents one third of the total taxes levied for the general municipal levy within the proposed BIA or expansion area, then the BIA by-law shall not be passed (MA, s.210(3)).

Municipal by-laws are also used to implement other significant BIA matters, including: the expansion of BIA boundaries, and the establishment of minimum, maximum, and special 
benefit charges. The boundaries of a BIA are typically determined by the natural limits of a commercial shopping precinct or the physical and/or historical characteristics of the area (MMAH, 2010, p.38).

The process to establish a BIA is at its core a grass roots idea driven by knowledge of local community needs and market forces within a designated commercial area. The unique position held by BIAs as a local board presents a real opportunity for local business leaders to pair local enthusiasm with municipal support to gain access to dedicated funding for long-range initiatives.

\subsection{Decision Making Hierarchy}

The decision-making hierarchy of a BIA is built around four key elements: provincial legislation, municipal authority, boards of management, and membership voting as shown in Figure 1. External to this, advocacy and advisory are offered by non-profit umbrella representation. With respect to provincial legislation, the establishment, operation and dissolution of BIAs is governed province wide by the Municipal Act, 2001, and in the Toronto context by the City of Toronto Act, 2006.

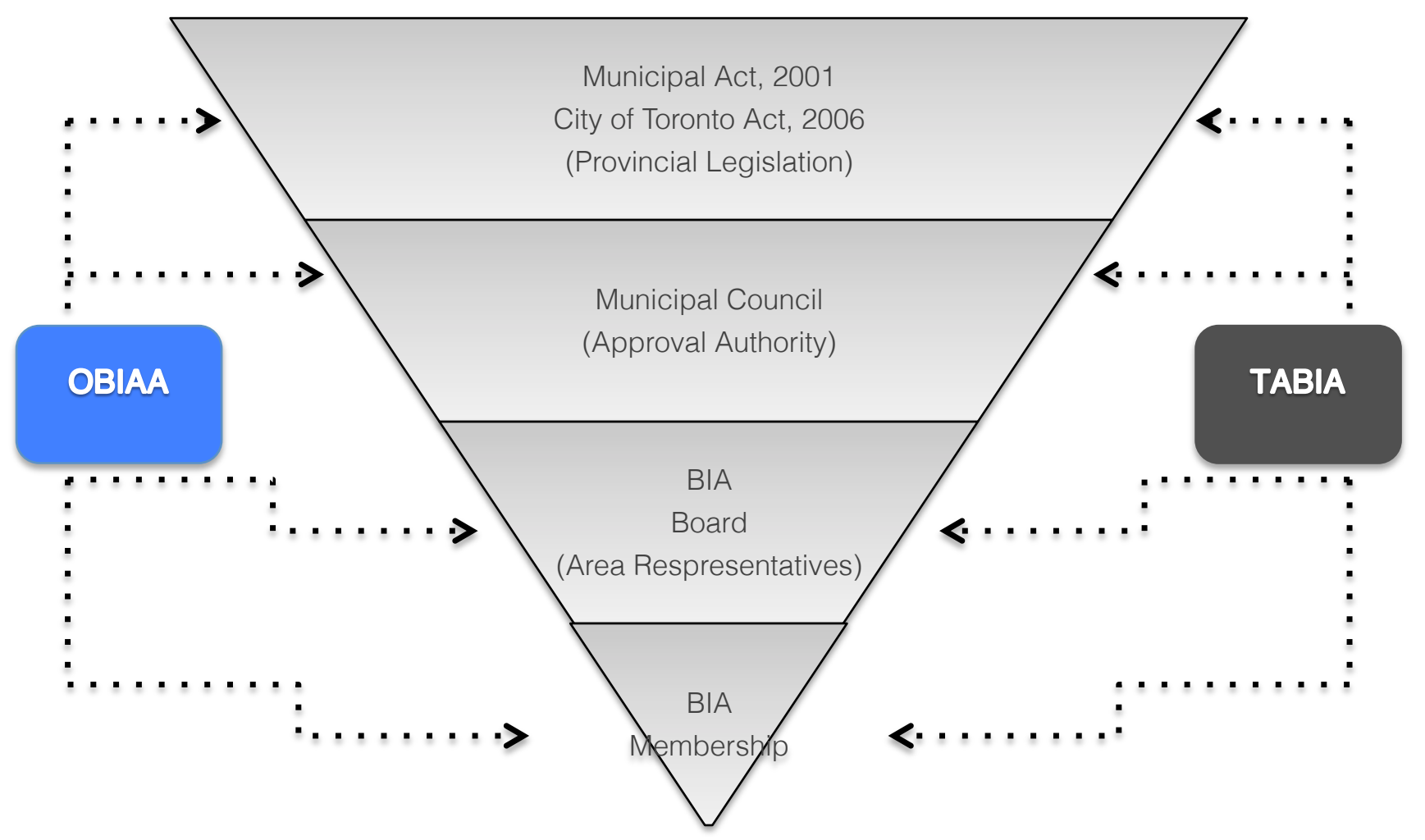

Figure 1: BIA Decision Making Hierarchy 
These two pieces of provincial legislation tie the BIA framework to the province. Beyond a legislative framework, the Province tends to act in an advisory role on the function and opportunity provided to BIAs.

Municipal authority over BIA organization also rests in the legislation. In particular Section 216 of the Municipal Act, 2001 outlines local municipalities ability to create special by-laws with respect to the operation and dissolution of local boards, which BIAs are considered to be.

Legislated as a local board of their municipality (MMAH, s.204), BIAs are required to meet regulated accountability and transparency standards with respect to decisions in the public interest and financial matters. Their operations may be subject to both financial and local record audits as well as meeting investigations where concern arises (MMAH, 2010, p.15). All agencies, boards and commissions of council are created to provide directed effort toward a particular focus of the municipality. In the case of a BIA, that focus is defined to be localized area improvements in the public realm and promotion of commercial activity. To give some context to the relationship between local boards and the municipality, Lucas (2013) was published in the IMFG perspectives publication, discussing local agencies, boards and commissions (ABCs) in Canada. He describes generally, that $A B C s$ are "...public agencies of limited purposes, operating locally or regionally, that are more or less formally separated from the ordinary council-committee structure" (p.2). The paper goes on to recognize that "Across Canada, thousands of local ABCs are performing important tasks in dozens of widely varying policy fields" ( $p .3)$, but that their arms length relationship often calls in question their governance and accountability. These perceptions will be explored throughout this study.

BIA membership includes all commercial property owners and tenants and may also include non-governmental organizations (i.e. churches) within the designated area. As guided by the legislation, each member of a BIA has one vote toward the appointment of a board of management regardless of the number of properties they may own or operate within the designated area. Members do not vote on budgetary matters once a board of 
management is appointed, but are able to discuss proposed annual budgets at a meeting organized by the appointed board (MA, 2001, s.205 (1)).

A BIA board of management is typically comprised of one or more directors appointed by the municipality, with the balance selected by vote from the membership and appointed by municipal council (MMAH, 2010, p.21). Their term of appointment must be consistent with that of the council in session and board members are subject to selection and appointment at the end of the term (MMAH, 2001,s.204 (10)). It is quite common for the local councillor to be appointed as a board member of the BIA, and in fact mandatory in the City of Toronto (MMAH, 2010, p.21). This direct relationship helps to link the efforts of the BIA with council priorities, and vice versa. Once established the board of management is responsible for administration of BIA operations as well as the creation and submission of the annual budget to Council for approval. The board of management acts as the 'face' of the BIA and represent the interests of the district in broader municipal and regional discussions.

External to the local BIA function, the Ontario Business Improvement Area Association (OBIAA) is a provincial non-profit umbrella organization representing the broader interests of BIAs across the province. OBIAA acts as a resource for training, promotion, and collaboration with the aim of advocating for small business and enhancing local BIAs contribution to the "economic, cultural and social well-being of communities in Ontario" (OBIAA, 2015). While the work of OBIAA reflects the broader interests of local BIAs across the province, the organization is membership based, with local BIAs voluntarily pay a nominal fee to become part of the organization. There are a total of 305 BIAs across Ontario, with OBIAA 2015 data showing roughly 235 member BIAs representing 67,085 property tenants and 9,363 property owners. (personal communication, 2015).

The Toronto Association of Business Improvement Areas (TABIA) acts as a similar umbrella organization for the local BIAs within the City of Toronto. There are 81 BIAs within the City of Toronto alone, representing over 35,000 businesses and property owners (TABIA, 2015, n.d). 
The decision-making framework around BIA practice outlines evidence of the power structures within the organization. Once created, a BIA becomes an entrenched entity of the municipality through legislation, but still built on the energy and advocacy of business. Finding the balance between local business membership and municipal interest rests entirely with the appointed board of management, highlighting their importance in the overall success of the district.

\subsection{Government Involvement}

In order to understand the role that Business Improvement Areas are playing in local community planning it is important to establish a clear picture of the governance structure guiding both the function of BIAs, and broader community planning practice to see where they align or fail to connect. Figure 2 below outlines the various levels of government involvement in BIA practice.

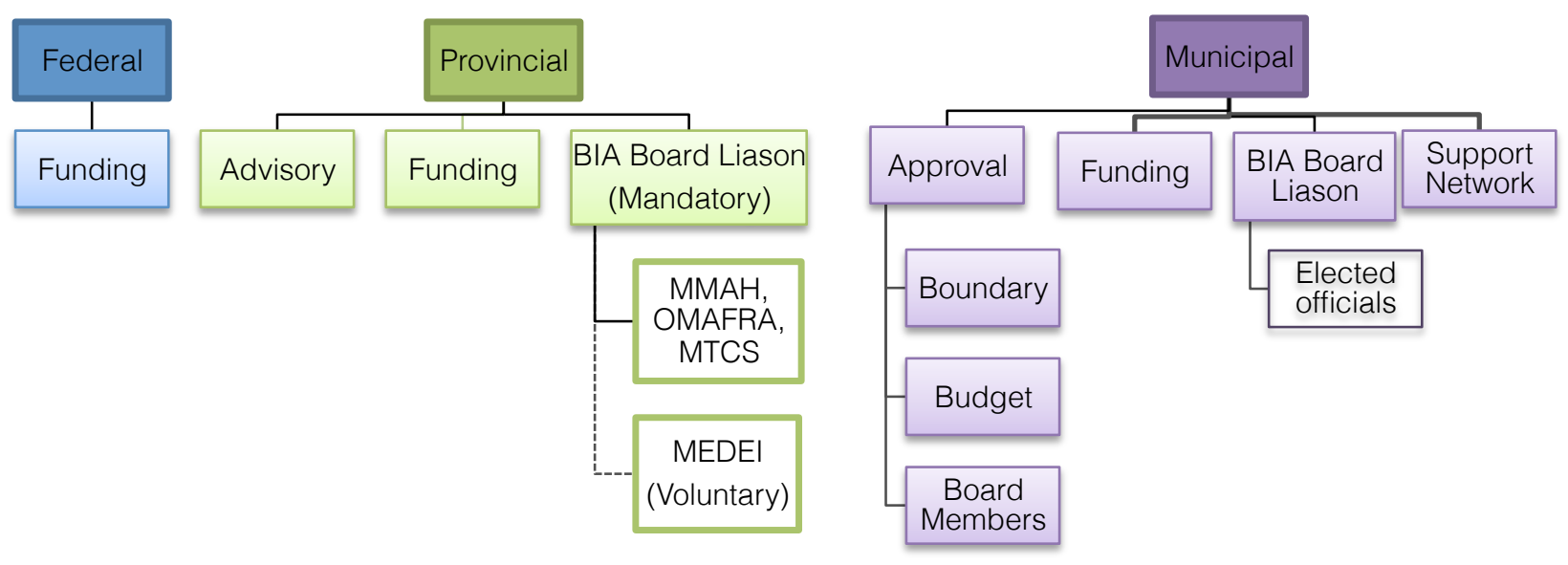

FIGURE 2: GOVERNMENT CONNECTIONS

Each level of government has a varying role to play in the work of BIAs across the province. Federal government involvement the work of Business Improvement Areas is typically through funding grants and capital works projects that intersect within a BIA district. There is no obvious direct line of communication with the Federal government. BIAs are therefore reliant on their own research or communication with the municipality or province to keep them informed on funding or capital works opportunities. 
The Provincial government in contrast was at one time closely tied to the establishment, operation and funding of Business Improvement Areas, that involvement with BIA work has evolved over time (personal communication, 2015). While Provincial legislation still establishes the operational and legislative framework for BIAs, their creation, budgetary requirements, revenue source and dispute resolution are a municipal responsibility. During the Harris government years in the late 1990s provincial downloading drastically reduced the funding opportunities and human resources available through the province across a number of ministries. In addition, the Municipal Act changes in 2006, established recognition of municipal control over the operation of local boards, including BIAs, further distancing the province from day-to-day operational matters. The continual evolution of this relationship between the province and BIAs brings us to today, where the province tends to act in more of a liaison and advisory role, providing workshops and training on the legislative requirements of being a BIA, representation on BIA boards, and input into the Municipal Act, 2001 legislation. The province currently has representation from three ministries on the OBIAA Board of Directors, including: The Ministry of Municipal Affairs and Housing (MMAH), the Ontario Ministry of Agriculture, Food and Rural Affairs (OMAFRA), and the Ministry of Tourism, Culture and Sport (MTCS). The Ministry of Economic Development, Employment and Infrastructure (MEDEI), began its collaborative relationship with BIAs through the provincial Open for Business strategy. In 2013, Business Improvement Areas were asked by MEDEI to take part in an Open for Business roundtable and identify five priorities under provincial jurisdiction that could strengthen the success of BIAs across the province. The Open for Business forum allowed BIAs to communicate the needs of the industry and in turn gave the province a direct understanding of the barriers to economic growth at a local level. One of the outcomes of this forum was an agreed annual meeting between BIAs and other provincial ministries through the PERL Secretariat (Planning, Environment, Resources and Land Use).

In the 2006 update to the Municipal Act (2001), municipal governments were provided the authority to dissolve or change a local board under Section 216, which includes BIAs, and amend any operational or administrative matters by By-Law (personal communication, 2015). Some larger municipalities with many BIAs, such as Toronto (81), 
Hamilton (13) and Ottawa (11) have an overarching BIA office, or BIA liaison on staff to address operational or budgetary questions over the course of the year. Where no designated office exists, BIAs are typically directed through the City clerks office or the economic development department for day-to-day queries and any municipal support requests (personal communication, 2015).

\subsection{Levy Payments}

The BIA levy, hereafter referred to as 'the levy', is a mandatory fee payable by commercial property owners and their tenants within the defined geographical limits of the BIA (Gomez, 2015). The levy forms a component of the property owners annual municipal tax assessment, and is paid directly to the municipality. The amount charged is determined annually by the BIA Board through the BIA annual budget and passed through Council prior to coming into effect. It is reflected either as a percentage of the overall assessed property value of commercial or business class land within the BIA, or as a dollar amount. The Municipal Act, 2001 legislation outlines the parameters of fee determination in Sections 205, which include the ability to set minimum and maximum levy rates. The City of Toronto Act, 2006 outlines the same in Section 19-34.

The mandatory nature of the levy could be considered a foundational element of current BIA structure, given its relevance in the initial discussion of BIA creation. The levy allows for a guaranteed source of revenue to enable delivery of operations, capital improvements and social programming. In Ontario, 2015 figures show the total assessed value of property within the BIA Area as by-lawed by each municipality stands at $\$ 60.9$ billion (OBIAA, 2015), demonstrating the substantial real estate portfolio BIAs represent.

To give some context the range of communities BIAs function in, the smallest levy collected by a BIA is reported at $\$ 6,611.00$ annually, and $\$ 40$ per tenant. The largest levy for a BIA is reported to be $\$ 3,550,416.00$, with the highest levy payment by tenant standing at $\$ 9,800.00$. The amount of the levy payment dependent on the size of community, the number of taxable properties within the BIA district and the annual budget required. The average levy payment across the province per tenant/per annum is 
estimated at $\$ 750.00$ (personal communication, 2015). It should be noted that these values reflect the reported figures of OBIAA members in 2015. Where no industry response has been provided, values noted are subject to inaccuracies.

These figures help to demonstrate the range of budgets available to BIAs across the province and the scale of financial contribution made by some property owners toward BIA initiatives. The values reflect a broad spectrum of financial capacity for BIAs to involve themselves in local community development implementation, and a considerable contribution required by independent business. These two factors both lend themselves to the observed disparity in practice, and may influence the ability for BIA Boards to initiate community based projects in the interest of continued and immediate return on investment for their membership.

\subsection{Organizing Business: Exploring alternatives to the BIA model}

Given the many different ways business owners may choose to represent their interests in both independent success and community well being, it is no surprise that there appears to be a lack of clarity on the benefit to business and community of establishing a BIA.

A comparison of the foundations, membership and mechanics of other organizational structures is provided in FIGURE 3. It may to alleviate confusion around the overarching benefit of BIAs. 


\begin{tabular}{|c|c|c|c|c|}
\hline Type & $\begin{array}{l}\text { Business } \\
\text { Improvement Area } \\
\text { (BIA) }\end{array}$ & $\begin{array}{l}\text { Municipal } \\
\text { Service Board } \\
\text { (MSB) }\end{array}$ & $\begin{array}{l}\text { Municipal Service } \\
\text { Corporation (MSC) }\end{array}$ & $\begin{array}{l}\text { Chamber of } \\
\text { Commerce (CoC) }\end{array}$ \\
\hline Formation & $\begin{array}{l}\text { Local Board of a } \\
\text { Municipality. }\end{array}$ & $\begin{array}{l}\text { Body corporate } \\
\text { and } \\
\text { Local Board of a } \\
\text { municipality. }\end{array}$ & $\begin{array}{l}\text { Corporation of a } \\
\text { municipality. } \\
\left(^{\star}\right) \text { An Economic } \\
\text { Development Corporation } \\
\text { is considered a Local } \\
\text { Board of a municipality. }\end{array}$ & $\begin{array}{l}\text { Volunteer } \\
\text { Organization }\end{array}$ \\
\hline Legislated & $\begin{array}{l}\text { Yes } \\
\text { Municipal Act, } 2001 \\
\text { s.204 }\end{array}$ & $\begin{array}{l}\text { Yes } \\
\text { Municipal Act, } \\
2001 \text { s.195 }\end{array}$ & $\begin{array}{l}\text { Yes } \\
\text { Municipal Act, } 2001 \\
\text { s.203 and O.Reg.599/06 }\end{array}$ & No \\
\hline Area Served & $\begin{array}{l}\text { Defined Geographical } \\
\text { Area }\end{array}$ & $\begin{array}{l}\text { Inter- } \\
\text { jurisdictional }\end{array}$ & $\begin{array}{l}\text { The boundaries of a } \\
\text { municipality with the } \\
\text { agreement of the } \\
\text { municipality. }\end{array}$ & $\begin{array}{l}\text { No legislated Defined } \\
\text { Geography }\end{array}$ \\
\hline Membership & $\begin{array}{l}\text { Business owners and } \\
\text { tenants of commercial } \\
\text { property within the } \\
\text { defined area of a BIA. }\end{array}$ & $\begin{array}{l}\text { At the discretion } \\
\text { of the } \\
\text { municipality, but } \\
\text { there must be at } \\
\text { least two } \\
\text { members. }\end{array}$ & $\begin{array}{l}\text { At the discretion of the } \\
\text { municipality. }\end{array}$ & $\begin{array}{l}\text { Local business } \\
\text { owners and } \\
\text { operators, elected } \\
\text { officials, industry } \\
\text { executives and active } \\
\text { citizens. }\end{array}$ \\
\hline $\begin{array}{l}\text { Legislated } \\
\text { Objective }\end{array}$ & $\begin{array}{l}\text { Improvement, } \\
\text { beautification and } \\
\text { maintenance of the } \\
\text { designated BIA area, } \\
\text { and promotion of the } \\
\text { area for business. }\end{array}$ & $\begin{array}{l}\text { Control and } \\
\text { Management of } \\
\text { activities as } \\
\text { defined by the } \\
\text { municipality }\end{array}$ & $\begin{array}{l}\text { Provide a system, service } \\
\text { or thing that the } \\
\text { municipality itself could } \\
\text { provide. } \\
\left({ }^{\star}\right) \text { Economic } \\
\text { Development } \\
\text { Corporations may } \\
\text { undertake activities to } \\
\text { further the economic } \\
\text { position of the } \\
\text { municipality, including the } \\
\text { purchase, disposal and } \\
\text { development of land. }\end{array}$ & $\begin{array}{l}\text { Build business } \\
\text { networks and } \\
\text { opportunities for } \\
\text { economic growth } \\
\text { through the promotion } \\
\text { and development of } \\
\text { commercial and } \\
\text { industrial } \\
\text { opportunities within a } \\
\text { larger city region. }\end{array}$ \\
\hline $\begin{array}{l}\text { Fees and } \\
\text { Levies }\end{array}$ & $\begin{array}{l}\text { Determined through } \\
\text { the annual BIA budget } \\
\text { approved by Council } \\
\text { and payable by all } \\
\text { members. }\end{array}$ & $\begin{array}{l}\text { Budget and } \\
\text { financial } \\
\text { reporting as } \\
\text { defined by the } \\
\text { municipality. } \\
\text { User Fees and } \\
\text { Charges } \\
\text { applied. }\end{array}$ & $\begin{array}{l}\text { No fees charged. } \\
\text { Budgetary requirements } \\
\text { are funded through } \\
\text { securities/bonds issued } \\
\text { by the municipality. }\end{array}$ & $\begin{array}{l}\text { Annual corporate } \\
\text { membership fee as } \\
\text { determined by the } \\
\text { Chamber executive. } \\
\text { Required payment for } \\
\text { membership. }\end{array}$ \\
\hline
\end{tabular}

FIGURE 3 - COMPARISON OF BUSINESS STRUCTURES 
A discussion around these forms of business organization is provided in Appendix A. Through this comparison, the BIA model gains traction in its ability to leverage guaranteed revenue through levy payments, the administrative power of municipalities, and the social capital of entrepreneurs.

\subsection{Current State of Research on BIAs}

Existing academic research into the application and success of BIA practice, in particular, within the Canadian context is limited. Further still, research that explores the influence of BIAs within the community-planning framework is even more challenging to find. While there is a great deal of opinion and editorial work done on projects involving the work of BIAs, these efforts are generally project specific or opinion based, and often relate to a specific geography, making it difficult to relate to BIAs in other communities. This literature review focuses on work (both peer reviewed and independent) presented in the North American context, and identifies common threads of research in the field of Business Improvement Areas.

Two pieces of critical analysis exist in the Canadian context in fulfillment of similar academic pursuit - Isakov (2009) and Green (2010). Isakov (2009) outlines the organization of BIAs in British Columbia in an effort to provide greater understanding of their existing structures, activities and accountability measures (p.iii). It importantly catalogues the vested interests, most prominent activities, and major challenges of the 57 BIAs in British Columbia at the time of publication. Green (2010) specifically looks at ten commercial corridors in the City of Ottawa, to assess the success of BIAs in attracting people to commercial mainstreets. It does this using a core indicator of pedestrian counts as a determinant of street vitality, with a number of variables (such as land use, demographics, and BIA levy investment) used as controls. The substantial work of Lorlene Hoyt dating from 2001 extends our jurisdictional knowledge to the United States where the Business Improvement District (BID) concept has been in place since the mid 1980s. Hoyts work examines the impact of BIDs on the urban landscape, and compares and contrasts the administrative structure of BIDs in specific jurisdictions. 
Beyond these studies, the more recent publication of Small Business and the City by Rafael Gomez, Andre Isakov, and Matt Semansky (2015) offers comparative study into the work of BIAs in the Toronto, Vancouver and Halifax settings. Their findings on the influence of BIAs in each jurisdiction offer clear and collective insight for municipalities, public bodies, and private sector stakeholders to consider as we look to find ways to advance the capacity of the current BIA framework. Finally, the Canadian Urban Institute (CUI) completed a study entitled the Value of Investing in Canadian Downtowns in 2013. This work highlights the reinvigorated provincial, municipal and industry interest in mainstreet and downtown investment. It details best practice examples of mainstreet and downtown revitalization in ten (10) Canadian cities. Collectively this literature offers common threads of understanding around the success and challenges experienced by within BIA districts, and research topics addressed to date. The common threads give weight to the core ideas behind this research. These are discussed below.

\section{The Importance of Small Business precincts in Cities}

The Canadian Urban Institute (2013) prepared the first report of its kind in Canada, to reflect the resurgence of downtowns and traditional commercial mainstreets as important historic artifacts of our cities evolution and places for entrepreneurial growth. The report categorically states that it “... aims to inspire and inform city builders, with many excellent and innovative approaches to downtown revitalization that are being applied across the nation" (CUI, 2013). The study goes onto point out the relevance of these places to the identity of cities and towns alike - as economic engines, heritage landmarks, and identity makers. "...downtowns are highly visible and valued by the population of the wider city as hubs for social and cultural activity" (CUI, 2013,p.21). The recent publication by Gomez, Semansky and Isakov (2015) helps to cement the critical role small-scale business plays in regional and national economic wealth based around observations toward a "Main Street Agenda “ (p.206). The observations presented are four fold. Small business employs people, not capital; economic resilience requires the adaptive nature of small enterprise to flourish; distributed and localized decision making spurs innovation; and the creation of new small enterprise plays a particularly important role in sustained economic growth (p.209). Through these observations the text asks policy makers to 
shift their focus to the power that exists in small business enterprise, and the collective power realized through their organization as a BIA.

\section{BIAs as Local Economic Development Agents}

Gomez, Semansky, and Isakov (2015) share cases that raise the possibility of BIAs making new contributions in the landscape of local economic development, pinning the BIA model at the heart of local economic growth, despite the road blocks and perceptions that exist in each context. For example, the creation of the Bloor West Village BIA “...significantly contributed to the entire community's economic vitality and the solidification of the municipal tax base" (p.51). More generally, the study notes that BIAs work to retain spending and investment within a localized area, thus reducing "economic leakage" from local economies and protecting mall-scale merchants (p.51).

Hoyt (2001) furthers this discussion in Untold Stories and Substantiated Impacts, by equating the BID concept to the various elements of a special purpose district, special assessment district and special zoning district. Like BIAs in Ontario, the report notes that BIDs draw the majority of revenue from additional tax on property owners within their boundary. Also similar to BIAs, BIDs provide an entirely localized level of enhanced service delivery. Her work highlights that "Like special zoning districts, most BIDs form when business and property owners seek to protect their interests" (2001, p.9). Given that business interest is generally concerned with the assurance of continued revenue and patronage, the work of a BIA inherently becomes grounded in local context and focused on protecting / promoting economic vitality.

Isakov (2009) delves further into the priorities of BIAs in British Columbia. His work indicates that over $50 \%$ of BIAs in BC listed their top priority as "Increased Security" with, "Branding and Marketing" and "Enhancing Maintenance" as the other top priorities for most BC BIAs. (Isakov, 2009, p.29). Beyond that, "Accessibility", "Recruitment of new business" and "Coping with competition" were of lesser concern to the BIAs surveyed. The findings confirm that in the BC context the assurance of safety, enhancement of aesthetic appeal and continued business promotion are the main functions of BIA groups. 


\section{BIAs in Community Planning Practice}

The majority of the literature, with the exception of Green (2010), supports the premonition of a shift in focus for BIAs toward community development initiatives. Hoyt (2001) agrees that BIAs play a role in community development practice through her discussion on the theoretical underpinnings of BIDs in the United States. She cites the urban theories of Jane Jacobs, in Death and Lift of American Cities (1961), and Oscar Newman, in Defensible Space (1972). Both examined the relationship between human behaviour and public space, promoting the theories that "... supervision of public spaces deters criminal activity and the physical design of public spaces affects criminal activity, respectively" (Hoyt, 2001, p.21). BIDs are suggested to address these theories through their programs, which enhance the physical appearance of public spaces, and increase surveillance through human activity, and in doing so, become place-making agents. Gomez, Semansky and Isakov (2015) further this reflection on the BIAs ability to foster more than business revenue and also generate social capital through supporting small business. They attest that the cumulative "...loss of more human scaled gathering places has a major impact on a community's level of social capital" (p. 201). Where BIAs are the stewards of our nations most extensive and valuable public gathering places, they also act as the first line of defense in protection of mainstreet vitality. This work goes on to stress the community benefits brought about by BIA creation, through the provision of additional services at little or no cost to local residents living adjacent to the BIA district, and their focus and encouragement of "localization and local economies" (p.104).

The findings of Isakov (2009) help to advance the idea that BIAs are important agents of community development practice. His work identified that the planning concerns of BIAs in British Columbia tended to focus on the challenges associated with transit and more strategic planning of the appropriate mix of uses in BIA locations. Their interest in meeting the needs of the neighbourhood addressed by strategic planning.

As mentioned, Green's (2010) work stands alone, in its ability to reflect the nascent link between planning policy and BIA performance. Her 2010 study attempts to decipher BIA impact on community vitality through a measurement of pedestrian counts, and concludes that "BIAs do not substantially affect the number of people on the street. 
However, other variables such as density, availability of green and open spaces and wide sidewalks, play a key role in street liveliness" (Green, 2010, p.i). These inconclusive findings around the otherwise agreed upon signals toward community development reflect the influence that existing community context and infrastructure play in a BIAs ability to shift modal pattern and retail choice in consumers. Green (2010) goes on to recognize that in the absence of a set of measurable indicators there are limitations in her findings (p.38).

\section{The Challenges Faced by BIAs}

Isakov (2009) identifies seven (7) core challenges to facilitating great BIA outcomes in BC. These include: Mandate Renewal / Member Apathy / Social Capital Issues; Security / Social Issues / Maintenance; Streetscape / Land use planning; Budget Financing; Marketing; Advocacy; and Tax (Isakov, 2009, p.54). The study notes that “... based on the result it would be fair to conclude that member apathy is the most significant challenge facing BIAs in BC" (Isakov, 2009, p.54).

Hoyt's work goes on to reiterate the challenge of definition in the US context, namely as a result of the varying ways in which BIDs can be defined and generate revenue. Noting that, "The primary disagreement centers on whether the "financing mechanism" is mandatory or voluntary" (2001, p.9). In the Canadian context this reflects the difference between a Business Improvement Area with a mandated membership and levy payment, and a Business Improvement Association, with voluntary membership and payment. Regardless, her work in the US highlights the impact uncertainty can have on productivity.

Gomez, Semansky and Isakov (2015) offer most notably, that despite distance and varying jurisdictional differences, the issues BIAs face are much the same. Quantifying value, substantiating relevance, balancing public and private interest, and generating recurring revenue are persistent themes in the uphill battle to build local economic and community based resiliency. These common challenges provide an opportunity for policy makers to affect broad sweeping improvement in practice and presumably outcome of BIA initiatives through directed focus on the common issues presented. 
Green's (2010) study highlights some of the findings found in Gomez (2015) where her conclusion around the lack of universal indicator system for BIA evaluation can result in poorly measured and reported success. The Canadian Urban Institute's (2013) work attempts to create a baseline for data collection to benchmark the performance of Canadian downtowns (and by extension mainstreets) through a set of indicators based around five core principles: Visibility, Visionary, Prosperity, Liveability and Strategy (p.11). The work recognizes the lack of existing parameters around data related to downtown vitality and "...highlights the importance of collecting data on the health of Canada's downtowns and the need to commit to this practice in the future" (CUI, 2013, p.9).

\section{Insights}

The academic research and existing literature available provides important insight into the relevance and field of practice of Business Improvement Areas in the North American context. The body of work verifies the importance of small business in both local and regional economies and further still recognizes the important role local mainstreets and downtown areas play in the community fabric. It builds knowledge around the idea that BIAs reside at the heart of local economic development and identifies BIAs as providers of enhanced local service delivery with a focus on private business, promotional activity for commercial prosperity, area safety, and aesthetic appeal. Through theoretical linkages to Jacobs (1961) and Newman's (1972) work connecting human behaviour to the surveillance and design of public space, BIAs are found to implement community development objectives through their focus on enhancing public space in both design and human activity. Beyond theory, the literature reiterates the position of BIAs as agents of community development in both the Ontario and North American context, through cited practical examples and a noted collective concern toward strategic neighbourhood planning. It also reveals areas of concern in the field, notably, quantifying relevance, generating revenue, member apathy, and balancing the public and private interest. All of which provide reference points for closer examination through this work. 


\subsection{Where We Stand: BIA1.0}

The historical context, jurisdictional scan and literature review to date have told us what BIAs are, about their growth over time, how they generate revenue, and where common threads exist in the successes and challenges of practice. This work confirms the basis of BIA work lies in the enhancement of the public realm, local service delivery, and promotion of commercial precincts for small business prosperity. The concept that started in Toronto continues to grow both locally and globally, with evidence to suggest that the focus is shifting. The literature provides evidence of BIAs position at the heart of localized community planning and economic development, and also provides examples of the challenges in practice. Despite their neighbourhood focus and influence, common challenges have emerged across North America. These extend from member apathy, and public mistrust, to competing public and private interests, generating revenue, and quantifying relevance. These recurring threads throughout the literature suggest the potential for common solutions. As this study aims to advance a progression framework for BIA2.0, where common solutions can be found they will be prioritized for the benefit of practice as a whole.

\subsection{Connecting the dots in theory and practice}

The next section of the study will further explore BIAs connections to community planning, and local economic development through an examination of principles and practice. Using key word searches and core definitions from each discipline a list of terms will be developed to establish where theoretical connections to BIA practice exist. Evidence of theoretical links will be highlighted from the field of practice.

\subsubsection{Community Planning and BIAs}

Community planning encompasses all facets of life. As a practice, it defines itself through its ability to conceptualize and promote places for people to live, work, travel and enjoy recreational activity in a sustainable and equitable way. Today community planners look beyond their traditional role of administering and organizing land use, to promote sustainable social, economic and environmental objectives in order to provide vital and resilient places to live. Building off the foundational work in the Bruntland Report, Our Common Future (1987), the guiding principles of sustainable community planning are 
four fold: Environmental Resiliency, Social Equity, Economic Health, and Cultural Vitality (UN,1992). These pillars drive the provincial policy framework that guides the management of land use and settlement patterns within the Province of Ontario. The Provincial Policy Statement (PPS) acts as the overarching policy framework for both urban and rural planning matters at a local level, and reflects the provinces directions for growth on a broad scale. The revisions to the framework in 2014 provide clarity and greater focus on the need for spaces that contribute to the vibrancy, health and sustainability of communities' physical and social assets over the long term with following vision for community planning practice:

"The long-term prosperity and social well-being of Ontario depends upon planning for strong, sustainable and resilient communities for people of all ages, a clean and healthy environment, and a strong and competitive economy" (PPS, 2014).

In the Ontario context, the importance of strategic community planning is well recognized and thoroughly entrenched in the regulatory framework. The translation of these policies into development and revitalization efforts across communities, neighbourhoods and town centres, requires strong partnership and collaboration between the public, private and non-governmental sectors.

Community planning objectives are distilled through municipal official plan policy to be implemented by municipal staff and key community members on the ground. BIAs, being comprised of business owners and operators, often represent many key community members in their membership. In this regard, BIAs have the potential to represent important agents of community planning implementation.

\subsubsection{Local Economic Development and BIAs}

Local economic development (LED) is a policy approach to addressing the reality that business and investment will shift locations to remain competitive in the broader marketplace (Swinburn, 2006, p.1). The practice of LED encourages the retention of economic growth and business success within a village, town, or city. It aims to enhance a regions competitiveness for new investment to create and ensure jobs, and generate income within a defined area. While the concept falls prey to an abundance of 
interpretation, it is aptly described in the World Bank Urban Development series (2006) to be:

The purpose of local economic development (LED) is to build up the economic capacity of a local area to improve its economic future and the quality of life for all. It is a process by which public, business and nongovernmental sector partners work collectively to create better conditions for economic growth and employment generation (Swinburn, 2006, p.1).

Roseland (1997) suggests a more contextual definition of community economic development referring to a "... process by which communities can initiate and generate their own solutions to their common economic problems and thereby build long-term community capacity and foster the integration of economic, social and environmental objectives" (p.3). LED strategies can range from improvements in hard infrastructure and wholesale area revitalization, to the creation of business support services and lowincome work strategies, or the establishment of financial incentives to attract new enterprise.

Successful LED is typically a joint collaboration between the public, private, and nongovernmental sectors. This allows for communities to ensure a prosperous business climate through appropriate policy creation and procedure by the public sector, while leveraging the wealth of skills, capital and people available in all three sectors to implement their vision. As Swinburn (2006) indicates, "Maintaining and sustaining such partnerships is often the critical and challenging factor determining the effectiveness of LED efforts" (p.4). In todays global economy the need for effective local economic development practice to retain talent and investment in local markets is imperative to the long-term success of a community. 


\subsubsection{The Intersection of theory and practice}

Using the list of key terms gathered from the PPS (2014), the Bruntland Report (1987) and Agenda 21 (1992), Roseland (1997) and Swinburn (2006), connections between theory and practice were identified. FIGURE 4 below offers a clear picture of how BIA practice aligns with the foundational principles of community planning and local economic development.

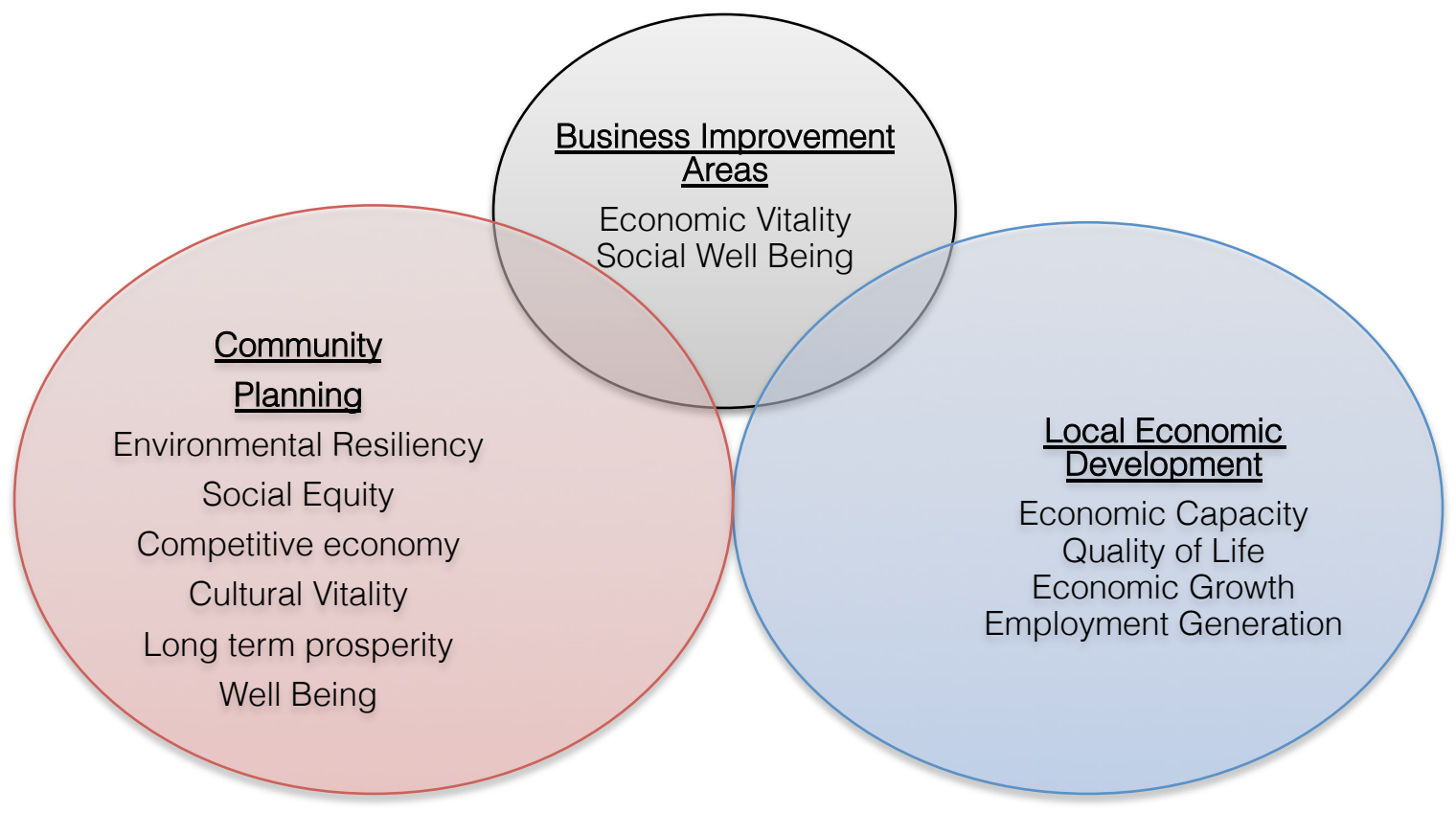

Figure 4: Aligning BiA Practice With COMmUnity deVElopment

Not surprisingly all three disciplines share a vested interest in economic vitality. This linkage connects the three disciplines across varying geographical scales - where community planning and local economic development aim to influence economic strength at either the regional or municipal scale, the work of the BIA is directly focused at the neighbourhood level. This spectrum of influence offers great potential for integrated solutions that recognize the business successes gained at a local level, impact the longterm economic vitality of broader municipalities and regions. The interest of municipalities to create job opportunities and economic wealth is inherently tied to the mandate that BIAs are carrying out locally. 
The other common thread is their collective focus toward social well being, and the overall quality of life within communities. This includes the assurance of access to facilities, parkland, social services, income equality, opportunity to participate in community based events, and ultimately fostering a connection to place. Where both community planning and local economic development aim to achieve this objective through policies and tools that facilitate well being, a BIA will encourage social well-being through its commitment to the public realm and community events. Where the approach is different, the intent is aligned.

These two specific elements of economic vitality and social well being provide a solid theoretical justification to examine the role BIAs are playing to facilitate community planning and economic development theory on the ground. These terms collectively will be referenced as "Community Development". As observed in practice too often these disciplines function in isolation of one another, which results in missed opportunities and limitations on outcomes. BIAs unique position at the axis of local planning and economic development puts them in a position to both convene and generate needed social capital at the neighbourhood scale. The first significant appearance of the concept of social capital was in the work of Jacobs (1961), where she used the term 'social capital' to describe a norm of social responsibility, a corresponding atmosphere of social trust and interconnecting networks of communication (Roseland, 2000, p.81).

This position places BIAs in at vital intersection in local communities, where a number of competing interests and influential stakeholders are also at play. As a result, the role a BIA plays appears inextricably tied to the development of vibrant, resilient, safe and prosperous communities.

\subsection{Is a new role for BIAs emerging? Reading signals from the field}

Using the attributes generated in FIGURE 4, a scan of practice has produced a number of noteworthy community development examples. Many BIAs are out there doing innovative and engaging work in their communities, and increasingly so. A select number of 
examples are presented to offer proof of the perceived trend toward more community focused practice.

\section{Social Well being - Planning for Public Infrastructure:}

Toronto's Financial District BIA (TFDBIA) prepared and implemented the first comprehensive public realm strategy for the Financial District of Toronto, Ontario in 2014/2015. Recognizing the area "occupies $0.1 \%$ of the city's land area, but generates $6 \%$ of the total property taxes and $15 \%$ of the jobs in Toronto" (Toronto Financial District BIA, 2015, slide 2). The significance of the BIA precinct to the broader population of Toronto, both in location and financial contribution to the tax base, demanded public realm considerations above and beyond the city standard. Through the use of planning techniques and collaboration with neighbouring BIAs, elected officials, the City of Toronto, and public utility service providers, TFDBIA undertook a broad based consultation effort. The public realm strategy built off of existing city right of way standards to establish a BIA-wide strategy on active transportation networks, new public transit shelters, and space allocation for food trucks, car sharing and other public amenities not typically considered in streetscape plans. Other non-standard enhancements like graffiti proof light pole wrapping, and ways to increase the tree canopy in the financial district brought a new aesthetic to the BIA (Toronto Financial District, 2015, slide. 11). This strategy serves as a prime example of the public benefit gained through a BIAs local knowledge, social capital and commercial influence.

\section{Economic Vitality, Supporting Local Entrepreneurship:}

Building on an initial concept created by the Uxbridge BIA in 2013, early 2015 saw Huron East Township in partnership with the Seaforth BIA, the Seaforth Brussels Community Development Trust, Huron Business Development Corporation and the Small Business Enterprise Centre to successfully administer their first Win This Space competition for local aspiring entrepreneurs (OBIAA, n.d).

Championed by the Township's Economic Development Officer the program offered business training, planning support and ultimately a new commercial space for the grand

prize winner. Spurred by an increased number of store vacancies along Seaforth's 
mainstreet, the winner located in one of the vacated storefronts. Creative funding solutions and tri-level government collaboration brought the project to life - with funding input from Federal (Community Futures Grant), Provincial and County sources, as well as countless private volunteer hours and donations. The projects has generated four (4) new business start-ups in Seaforth, offered training and mentorship to the 24 competition entrants, generated regional publicity for both communities, and “...catalyzed positive change in the business communities of Seaforth and Brussels" (Township of Huron East, 2015).

Social Well-being, Improving street vitality and safety:

The Spruce the Bruce campaign is a joint collaboration between Bruce County and the regions local BIAs and Chambers of Commerce to encourage investment and engagement in village downtowns and mainstreets. This County initiated program aims to make communities more attractive, pedestrian friendly, and distinctive. Recognizing downtowns and mainstreets "... represent over 2/3rds of commercial assessment and are the main point of contact for tourism dollars," (County of Bruce, n.d) the program focuses on education and grant funding to enable revitalization project implementation. As an example, the Kincardine BIA and Chamber of Commerce have benefitted from the program using grant money to repaint their historic lighthouse and make improvements to public space infrastructure (County of Bruce, n.d).

\section{Social Well Being, Equitable Service Provision:}

Recognizing that public benefit often initiates private benefit, a collaborative initiative between the City of London, Downtown London BIA and an active group of community members enabled the launch of London LAWN (London Area Wireless Network) providing free outdoor public wifi services throughout the downtown.

London LAWN is a collaborative venture between Downtown London [BIA] (funded by downtown businesses) and the City of London. Both organizations have invested in equipment and installation. Ongoing operating costs are funded by Downtown London. (LAWN, n.d.) 
The program is now one of the largest free outdoor wi-fi services in the country, and has successfully encouraged patronage in the downtown through the provision of a public service above and beyond traditional retail and commercial business.

\section{Insights}

In theory and practice a shift in BIA practice toward a more substantial role in community development continues to emerge. The linkage of BIA practice to the core objectives of community planning and local economic development is clear through the shared interest in economic vitality and social well being. Signals in the field also reflect BIA practice that goes above and beyond the mandate of beautification and promotion to facilitate outcomes that benefit more than independent business interests.

It would seem the transition to a new BIA2.0 framework is already underway. This study will resolve the indications of this shift through a closer examination of national awards submissions, analysis of primary interview findings, and a review of planning tools that influence current practice. The findings will establish the current state of BIA evolution, and frame next steps toward BIA2.0. 


\section{Examining the Shift}

\subsection{METHODOLOGY}

The study research methodology is broken down into three distinct parts: Award winning case study analysis, key informant interviews and an examination of planning tools. The use of triangulation as described by Erzberger and Kelle (2003) is employed in this study to seek three complementary viewpoints on the role of BIAs in order to present a more complete picture when analyzed together. This work achieved ethics approval from the Ryerson University Ethics Review Board on May 28, 2015 given the inclusion of primary interview subjects.

\section{Award Analysis}

Case study analysis was focused on the award winning efforts of BIAs selected through the annual National BIA awards. Using the methodology found in Parkinson and Roseland's (2002) evaluation of submissions to the Federation of Canadian Municipalities Sustainable Community competition, this study will examine the submissions made to the annual Business Improvement Area Awards. The method used by Parkinson and Roseland (2002) when applied to BIAs will produce a valuable snapshot of BIA best practice in the Ontario context using a systematic and clearly defined set of criteria and the benefit of industry driven acknowledgement of success. The idea behind award competition itself speaks to an outcome or an approach that deserves recognition. The fact that both the award categories themselves and the evaluation criteria were created by industry professionals allowed for an inside perspective on what BIAs themselves consider best practice. The use of an industry based evaluation aids in a deeper understanding of regional trends.

The general population size charted is reflective of Statistics Canada census data (2011) for the CMA area most associated with the location of the BIA. While the defined geographic area of a BIA is a subset of the broader census metropolitan area, the population statistics used reflect the potential population of the BIAs efforts. Where a BIA 
in Toronto has the potential to access a much wider population than a BIA in a smaller rural community.

The regional location of a BIA is categorized based on economic region. This method aligns with the break down of economic regions (West, Central West, East and North) supported through the Ontario Ministry of Agriculture and Rural Affairs (OMAFRA, n.d.) and then further categorized by upper or single tier municipality. It should be noted that where one BIA submitted under more than one category, there entry into the competition was only counted once. The award examination charts the location and size of municipalities represented by each submission, establishes linkages between the award categories and core principles of community planning and local economic development as outlined in FIGURE 4, and finally, highlights innovative ideas reflective of current best practice in the field. The data considered can be broken down into three types:

1) Descriptive data about the municipalities;

2) Descriptive data about the submissions;

3) Evaluation of the awards categories and measurement again community development principles.

\section{Key Informant Interviews}

The primary interviews for this study were conducted using qualitative techniques. Face to face interviews were completed with five key informants over a period of two months, along with two separate phone interviews. Where further correspondence was warranted with interview participants' email was used as the method of communication. The interviews were semi-structured, and included a pre-determined and approved set of questions attached for reference in Appendix C. The questionnaire was submitted to and

received approval from the Ryerson University Ethics Board prior to commencement of the interview process. Questions were framed in such a way as to draw out perceptions and opinion on current practice, benefit to both the public and private interest, challenges in implementation and governance, barriers presented in the legislation and access to funding. 
Key informants interviewed were selected based on their expertise in the history and practice of BIAs, and leadership qualities established through participation in BIA network activities. Interviewees included a range of provincial level policy advisors and economic development officers; municipal level planners and economic development officers; and both local and regional business improvement area executive staff. For the purposes of this exploratory research, identified participants have allowed for a comprehensive scan of the current context of BIA practice and areas of growth and improvement.

\section{Examination of Planning Tools}

Building on the insights gained through the awards analysis and key informant interviews the examination of existing provincial and municipal planning tools was completed on a selective basis. Where a particular planning tool was identified through the other methods of study, that tool was considered as part of this examination. While not an exhaustive analysis, the work aims to target those tools specifically utilized in practice to offer a more fine grain consideration of their current affects and future potential to advance BIA practice.

Combining the basic premise of both a Leopold matrix, commonly considered in Environmental Impact Assessment (Ponce, n.d.), and the Growth - Share matrix popular in business analysis (Hoetjes, 2010), a dual axes matrix was created to allow for consideration of the influence and type of planning tool. The Leopold matrix demonstrated the importance of both existing conditions and future influence in an overall assessment. It is the "... best known matrix methodology available for predicting the impact of a project on the environment" (FAO, n.d.). The Growth - Share Matrix then displays that relationship of cause and affect in quadrants (Hoetjes, 2010, p. 43), allowing for adaptation to this study. 
Hoetjes (2010) confirms the relevance of this evaluation methodology to urban planning practice,

... I find that the Growth-share matrix is a suitable source of inspiration for current urban planning challenges because it enables the mapping of the market dynamics in the city in a relatively simple way. More importantly, following Minztberg, this analogy provides no solutions by itself, but rather a framework for further deliberation and consideration of more sophisticated discussions of investment decisions (p.46).

For the purposes of this planning tool evaluation, numerical values will not be attributed to the position of influence within the matrix given the exploratory and qualitative nature of the work. The first set of determinants considered were whether the tool has a positive or negative influence over BIA practice. Where a legislated policy or tool with a positive influence is considered to have the ability to further the opportunities for a BIA to implement community planning principles, namely economic growth and social well being, on the ground. These tools create incentives, generate funding, establish needed regulation in practice, or advance the potential for collaboration between BIAs and other stakeholders.

A legislated policy or tool with a neutral influence is considered to have regard to the actions or intended outcomes of a BIAs work, but be neither persuasive nor controlling in its language or accessibility. Where neutral policies and tools exist regard should be had to their 1) necessity, and 2) amendment to generate a more positive outcome. A legislated policy or tool with a negative influence is considered to have the ability to limit or eliminate opportunities for a BIA to deliver community-planning principles at a neighbourhood scale. These tools have the potential to restrict and or deter positive community action led by the BIA. It is important to note that reference to "positive" and "negative" influences are not synonymous with the terms "flexible" and "restrictive". On the contrary, some positive policies may be those that control or limit the geographical boundary of a BIA or establish a clear management framework. It is worthwhile to keep this context in mind as the analysis unfolds. 
The second set of determinants considered whether the tool was a 'control' or an 'incentive' in the advancement of BIA practice. Where a 'controlling' planning policy or tool places certain restrictions on land use which will influence the actions and or success of a BIA, and an 'incentive' planning policy or tool will encourage particular decisions around land use that will influence the actions or success of a BIA over the long term.

\subsection{Study Limitations}

There are limitations to consider with each of the research methods employed. These are outlined in order to frame future discussion of the findings. OBIAA reports and presentations offered the primary, and in most cases only source of data for award analysis. They are of themselves considered to be a constraint on the findings given the sole sourcing, and the investigator's limited understanding of qualification criteria for award submission in the first place. While the awards reflect best practice within the BIA industry, the acceptance of submissions from non-BIA organizations has the potential to clutter the findings substantially. It is unclear the extent to which organizations outside of the BIA framework are involved in OBIAA annual awards. While unavoidable in this work, it is a cautionary note on the potential impact of the findings moving forward. Similar to Roseland and Parkinson (2002), the quality and detail of data given in the project descriptions is also reliant on secondary data sources and may lead to inaccuracies in this study's representation of best practice. In addition, this analysis does not adjust population values to account for the settlement patterns beyond those indicated by CMA population estimates.

The selection of interview participants and the voluntary nature of their participation posed some limitation on the primary interview process. Participants were approached either through the investigator's knowledge of work in the field or through suggestion by other participants, which may not reflect a random sample of the field of practice. Given time constraints for completion of the study, the opportunity to conduct a statistically significant randomized interview process was not possible. The primary interviews offer a sample of industry perceptions and are not meant to provide statistical conclusions. 
With respect to the examination of planning tools, the assessment of influence brings with it an element of subjectivity. The determination of positive or negative influence is bound by the knowledge and experience of the investigator. This limitation on the analysis is noted, but felt reasonable given the background research undertaken to ascertain the degree of influence from the field. Additional limitations are the generalities assumed in order to offer analysis relative to the broader Ontario context. Where review of locally specific documentation is based on the general assumption of certain policy inclusions that are consistent across all municipalities. For example, when speaking to Official Plan documentation, a general acknowledgement of the provision of policies related to commercial uses, street corridors, and employment will be made. The limitations of generalities result in a lack of contextual sensitivity in the findings. 


\subsection{Findings}

\subsection{National BIA Award Analysis}

The Ontario BIA Association and the Toronto Association of BIAs work together annually to recognize best practice around the province. The annual awards form part of the national conference program, and provide a framework established by peers within the BIA community, to evaluate the contributions BIAs are making on the ground. Using this award framework as a distinct set of data, an assessment of BIAs role in community planning and local economic development initiatives was completed. While the program and award listings have evolved over the last decade, in 2015 there were seven distinct award categories, said to reflect "the core priorities of most BIAs" (OBIAA 2015). They are described as follows:

\section{OBIAA and TABIA National Award Categories}

1. The Alex Ling + Lifetime Achievement Award, which recognizes individuals who have made a significant contribution to strengthening and promoting BIAs work and network.

2. Bricks + Mortar Award, which recognizes the impact of a particularly successful project completed by a private sector development partner within a designated Business Improvement Area. It aims to encourage cooperation between BIAs and the development sector.

3. Business Retention, Recruitment + Expansion Award, which recognizes the efforts of a BIA to understand the commercial context of their area, and actively identify and retain key business opportunities.

4. Main Street Accessibility Award is a brand new award for 2015. It recognizes both the BIA organization and the independent business that best implemented the new provincial Accessibility for Ontario with Disabilities Act requirements within the BIA.

5. Marketing + Communications Award, which recognizes project that improve the visibility of the BIA within the community and the vitality of the area itself through print, electronic or multi-media efforts.

6. Safe + Healthy Environment Award, which recognizes projects that have successful addressed pointed safety concerns within the BIA area and broader community. While also improving the opportunity for and access to more environmentally sustainable business practice through energy efficient technologies and strategies/programs for waste management reduction. 
7. Special Events + Promotions Award, which recognizes the ability of a BIA to successfully promote a unique event which enhances the image of the BIA. The event could benefit a range of BIA elements, such as organizational development, retail development or cultural history (OBIAA, 2009).

An appointed awards committee, representing a cross section of BIA professionals the province, using the established evaluation matrix, then assesses each submission.

Submissions are ranked on a scale of one to ten based on their ability to meet the four key criteria noted below:

- Innovation: Is the project or program innovative in its approach to a BIA management or development challenge?

- Transferrable: Would the solution, process or idea be replicable in other BIA jurisdictions?

- Inclusive/Representation: Has the project or program been inclusive of the community as a whole? Did the process involve the creation of community partnerships?

- Measurable Impact/Execution: Was the impact of the work measurable and significant? Did it ultimately achieve the goal it intended to? (OBIAA, 2015).

The OBIAA Awards scan provides the opportunity to examine the field of best practice in Business Improvement Areas across the province. As a peer reviewed awards competition, it evaluates BIA practice across multiple jurisdictions based on the common perceptions of internal experts. In this way, it offers a glimpse at what is generally considered best practice, and by extension, if these efforts are generally contributing to community development. Analysis of the submissions based on regional location, population size, and category of submission help to frame the state of Business Improvement Area practice across the province.

\section{Award Analysis Findings}

For the 2015 awards competition, there were a total of 21 submissions, representing $6.8 \%$ of the total number BIAs across the province (305). A considerably low turnout by all standards, but it is understood not to be dissimilar to other years (personal communication, 2015). 
Starting with a review of award categories themselves, we begin to get an indication of how industry experts view the intended purpose of BIAs. Through an evaluation of these categories the intent to celebrate BIAs capacity to implement community development is obvious. The categories themselves reflect a broader spectrum of community development components, while the evaluation matrix is well placed within the practice of sustainable community planning.

\begin{tabular}{|c|c|c|c|c|}
\hline Theory and & \multicolumn{4}{|c|}{ Award Categories } \\
\hline $\begin{array}{l}\text { Community } \\
\text { Planning } \\
\text { Objectives }\end{array}$ & $\begin{array}{l}\text { Safe \& Healthy } \\
\text { Environment } \\
\text { Award }\end{array}$ & $\begin{array}{l}\text { Mainstreet } \\
\text { Accessibility } \\
\text { Award }\end{array}$ & & \\
\hline $\begin{array}{l}\text { Business } \\
\text { Improvement } \\
\text { Area Core } \\
\text { Practice }\end{array}$ & $\begin{array}{l}\text { Alex Ling Lifetime } \\
\text { Achievement } \\
\text { Award }\end{array}$ & $\begin{array}{l}\text { Bricks and Mortar } \\
\text { Award }\end{array}$ & $\begin{array}{l}\text { Marketing and } \\
\text { Communications } \\
\text { Award }\end{array}$ & $\begin{array}{l}\text { Special Events } \\
\text { and Promotion } \\
\text { Award }\end{array}$ \\
\hline $\begin{array}{l}\text { Local Economic } \\
\text { Development } \\
\text { Objectives }\end{array}$ & $\begin{array}{l}\text { Business } \\
\text { Retention, } \\
\text { Recruitment \& } \\
\text { Expansion Award }\end{array}$ & & & \\
\hline
\end{tabular}

FIGURE 5: AWARD ALIGNMENT IN PLANNING AND ECONOMIC DEVELOPMENT

FIGURE 5 offers planning practitioners and policy makers visual evidence of the linkages between planning policy and BIA best practice. This connection is an important one, in that it ties the intent of BIA practice to a vested interest in the public good.

A very directed effort to encourage investment in the public realm is found in the creation of the awards category dedicated to accessibility. Updated provincial accessibility standards in 2012 under the Accessibility for Ontarians with Disabilities Act (AODA) called for physical infrastructure improvements with an attached timeline for implementation. These new standards require a direct and immediate response from commercial business owners. OBIAAs efforts to incentivize both independent business 
owners and BIAs through award recognition are notable. The public good is served as a result of these efforts, thus enhancing the overall vitality of the community. The award categories offer a clear intent to engage in broader community development initiatives.

A review of the four award evaluation criteria established by OBIAA and TABIA, also proves to link BIA best practice measurements with the basis for sustainable community planning. The BIA evaluation matrix aligns exactly with four of the six criteria for evaluation proposed in the Roseland (2000) Sustainability Awards paper. This symmetry speaks volumes for the approach that OBIAA and TABIA are taking toward rewarding success in the field on the basis of sustainable community indicators. The two missing evaluation criteria are termed "Long Term Viability" and "Part of a larger vision" (2000, p.417).

The "Long term viability" criteria assessed a projects ability to either sustain its active work over the long-term (i.e. a new program) by securing sufficient financial, human, social or ecological resources without risk of depleting them. Or sustain its reported outcome (i.e. a revitalization effort) over the long term through appropriate measures and implementation to ensure it won't fall apart. (Parkinson and Roseland, 2002).

The "Part of a larger vision" criteria was an important component of sustainable community based evaluation. It reflects a recognition that the project being considered, and potentially awarded as best practice in the field, is part of a complex and evolving system of political, social, and economic factors. This criterion requires demonstration of a holistic understanding of impacts that the project may have on all facets of the community - economic, social, cultural, and environmental. (Parkinson and Roseland, 2002).

Consideration of these additional criteria may be warranted should BIAs look to align themselves more firmly in sustainable community planning practice. Further discussion around this year's award winning projects has been highlighted in SECTION 4.0 on best practice BIA work. 
Further examination of the regional location and size of municipality highlights a somewhat more substantiated picture of where BIAs are choosing to engage in community development work. It varies substantially in both geography and scale. BIA engagement in community development work is both more urban than rural, and more frequently demonstrated in the southwest and Toronto than anywhere else in the province. FIGURES 6 AND 7 highlight the distribution of the 2015 submissions.

The vast majority of entries to the 2015 annual BIA Awards came from larger municipalities with a population of more than 100,000 people. $38 \%$ of the submissions were from BIAs located within the City of Toronto, $31 \%$ of submissions from the central west economic region, which surrounds Toronto, 19\% from the Eastern economic region, and $13 \%$ from the west. There were no submissions made from the northern economic region in 2015.

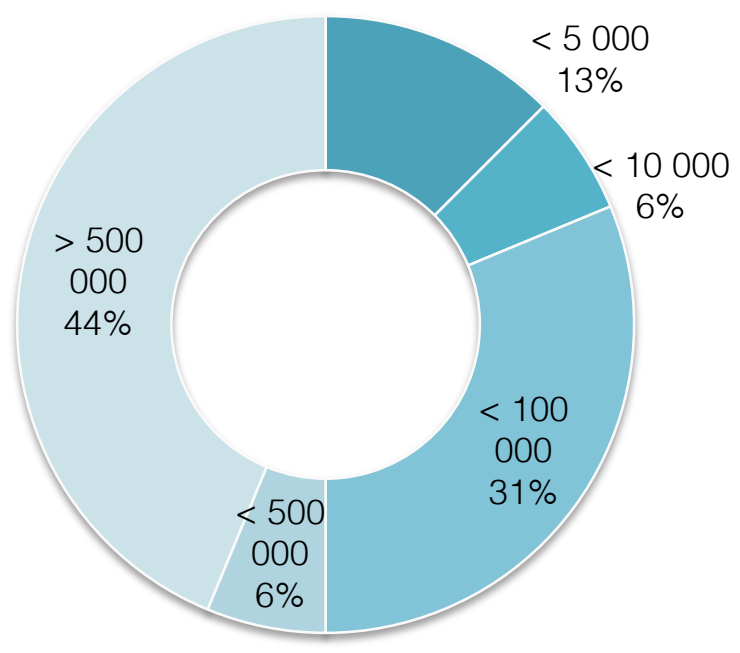

FIGURE 6: 2015 AWARD BREAKDOWN BY POPULATION SIZE

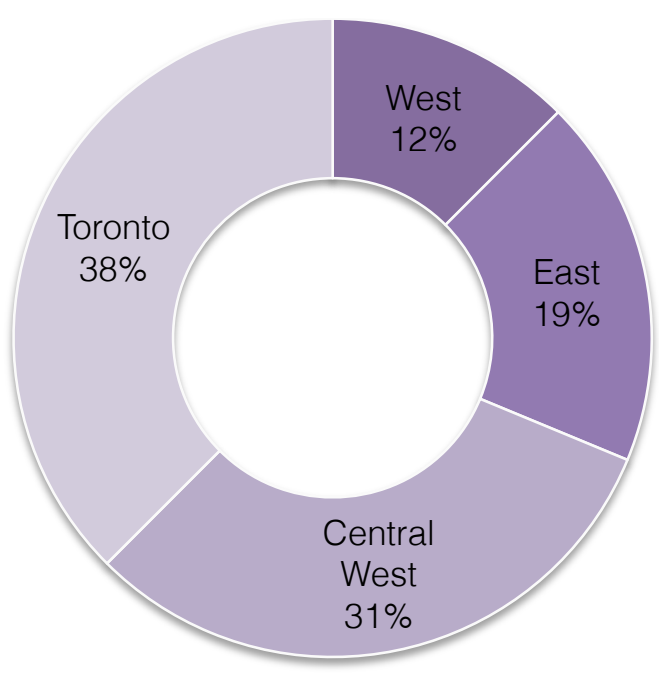

FIGURE 7: 2015 AWARD BREAKDOWN BY ECONOMIC REGION

Examining the spread of municipalities represented through the 2015 awards competition, the dominant number of applications (38\%) is again represented in Toronto. Beyond that, both Durham and Simcoe counties produced $13 \%$ of the total number of 
applications with the balance of singular submissions coming from a range of municipalities across the province as shown in FIGURE 8.

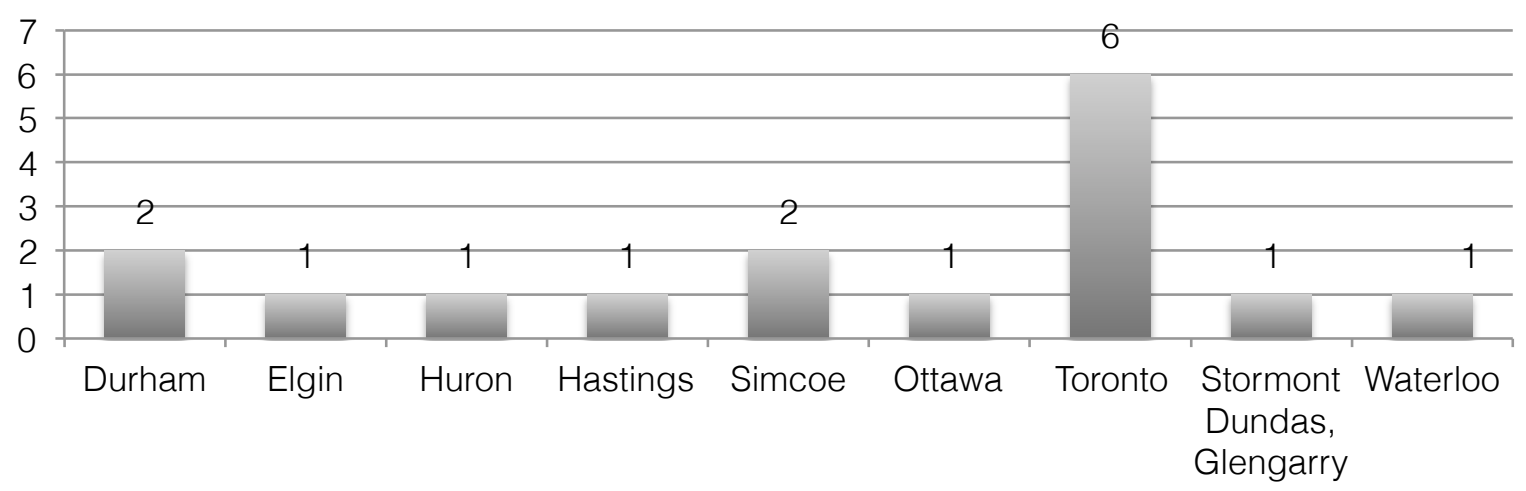

FIGURE 8: 2015 AWARD BREAKDOWN BY REGION, COUNTY OR DISTRICT

A similar exercise to track the location and size of municipalities for the award winning entries over time was completed using the data available for the period 2012-2015. FIGURES 9-11 show this analysis.

With this data, we see some slightly different trends over time. Analysis shows that while the majority of winners are still coming from larger regions with over 100,000 people, more specifically, they are coming out of areas with a population between 100,000 and 500,000 . These are the medium sized cities that dot the Ontario landscape. There were no municipalities represented with under 1,000 people and only $12 \%$ of winners coming from municipalities with less than 10,000 people.

In terms of representation from the five (5) economic regions, the largest percentage of winners is being produced in the Central West with $40 \%$ of the award winners over the past four years. Toronto BIAs comprise $28 \%$ of the total awards winners, and the west economic region $24 \%$. The eastern and northern economic regions of the province are equally represented with $4 \%$ each. 


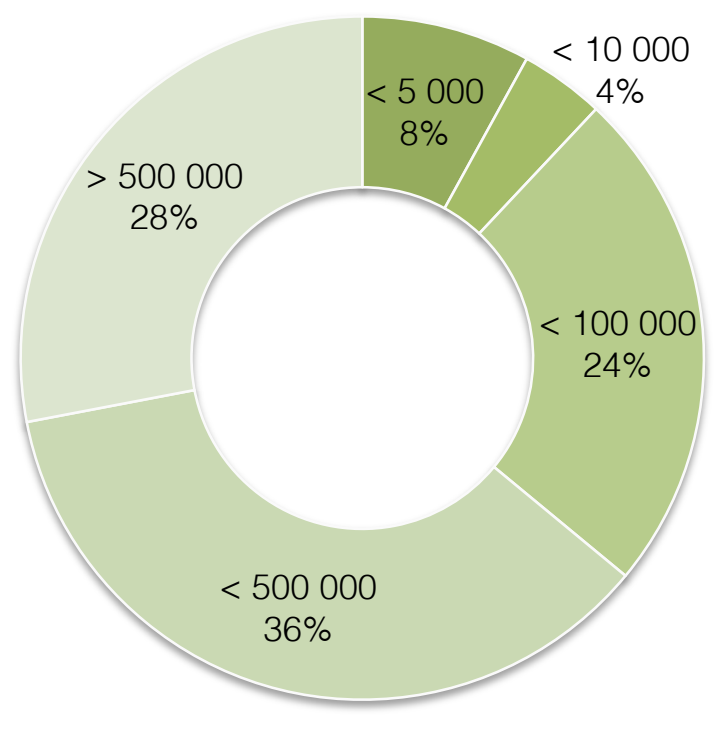

FIGURE 9: 2012-2015 AWARD

BREAKDOWN BY POPULATION SIZE

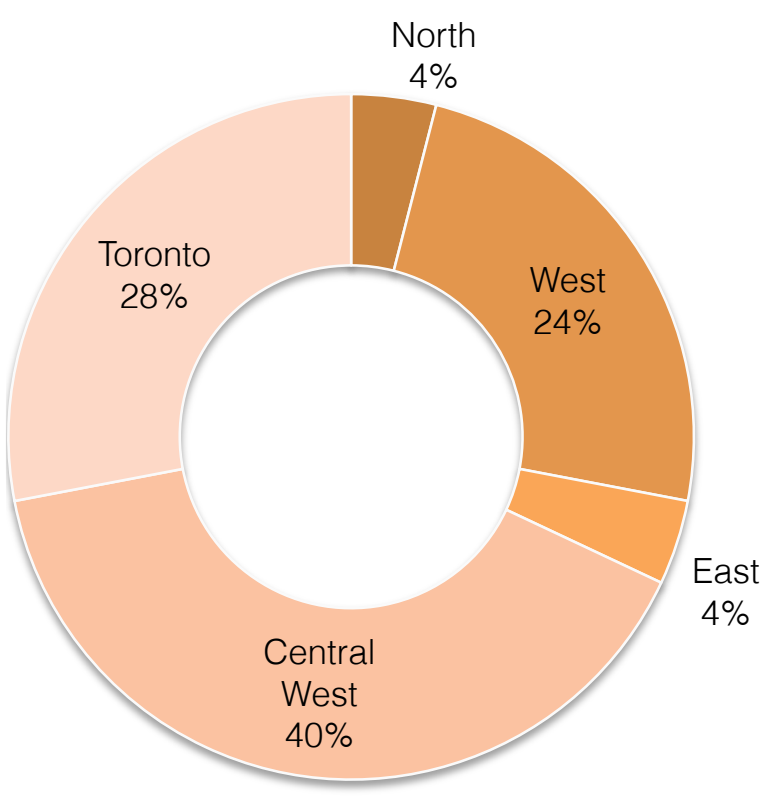

FIGURE 10: 2012- 2015 AWARD

BREAKDOWN BY ECONOMIC REGION

Drilling down further, the extent of award winners demonstrates the reach of the BIA model across the province. There are 15 different regional counties or districts represented by at least one best practice award winning BIA project. The City of Toronto still dominates, with a total of $28 \%$ of the awards since 2012 . But there are also a number of other municipalities represented, each with $8 \%$ of the total awards given, these include: Durham, Huron, Simcoe and Waterloo region.

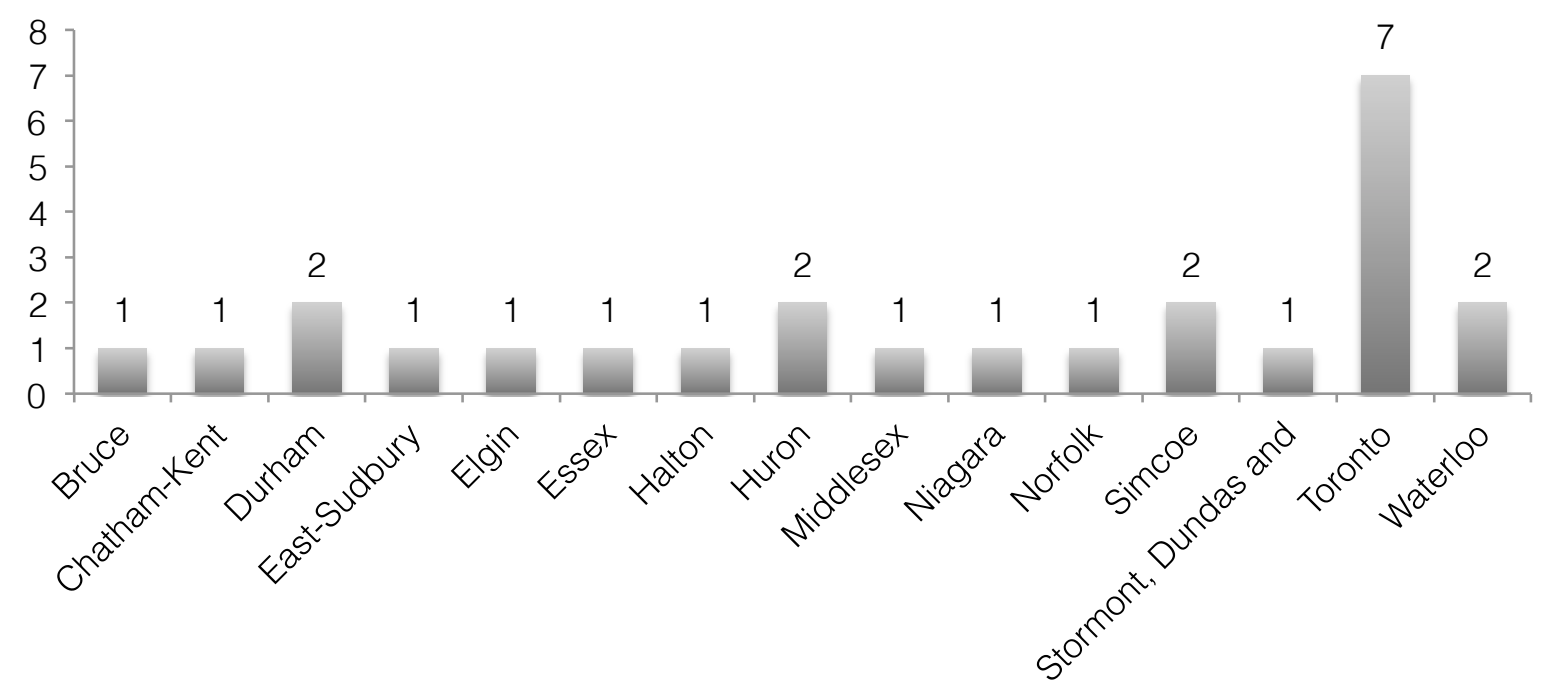

FIGURE 11: 2012- 2015 AWARD BREAKDOWN BY REGION, COUNTY OR DISTRICT 
The lack of representation from the northern and eastern portions of the province could be a reflection of the population of settlement areas, where BIAs tend to success in larger municipalities and neither the north or east has a great deal of larger settlement areas, or it could also reflect larger social and economic issues within those existing settlement areas. The award scan does not offer this insight.

Beyond intent, it is also relevant to examine the actual projects produced in the field. A review of the 2015 award winning BIA projects confirms without question that there are BIAs in the province directly implementing community planning policies on the ground. The Toronto Financial District BIA offers two examples. The first is their Raising the Standard Public Realm Strategy, the second their @MyTOFD communication campaign. Both benefit the general public above and beyond their membership base. Raising the Standard provided the financial district with its first long-range public realm strategy. It was developed with the benefit of extensive public consultation, and worked to encourage active transportation throughout the district. Key deliverables included connection of green spaces, mapping pedestrian linkages throughout the district, and enhancing the appearance and accessibility of the street and PATH network through way finding signage, aesthetic wrapping of hard infrastructure (TOFD, 2015, slides 7-10).

The @MYTOFD communications strategy goes beyond basic marketing and business promotion to provide users with notifications which enhance daily life - transit schedules, construction notification, public events, and a forum for public feedback (TOFD, 2015, slide 2). Through a focus on community building within the financial district the BIA is acts as a convener of social good and a practioner of community planning.

Collingwood's downtown revitalization and accessibility retrofit also provides a sound example of community development implementation. Where community planning policy must support access requirements under the Accessibility for Ontarians with Disabilities Act (AODA), the Collingwood BIA facilitated privately owned building retrofits and public realm improvements to implement these standards across its downtown. This work goes above and beyond the benefits assured to independent business and creates a 
community driven initiative, showcasing the BIA as a facilitator of community development and a practioner of community planning.

These three examples reflect best in class, and the varied scale and context within which BIAs are delivering community development work. Further investigation into breakdown of entries to each award category offers greater clarity around the vested interest of local BIAs across the province, or at least those that made the conscious decision to submit for an award. While there are understood limitations in the scope of this analysis given the sample size, it does provide a snap shot of where can reasonably be considered the most proactive BIAs in the field and their chosen area of focus over the previous year. FIGURE 12 highlights the number of submissions to each award category, and some fairly distinct preferences from the field.

\section{Award Category}

\section{\# Of Submissions}

(2015)

\begin{tabular}{ll}
\hline Marketing and Communication & 8 \\
Special Events and Promotion & 7 \\
Business Retention and Expansion & 0 \\
MainStreet Accessibility & 1 \\
Safe and Healthy Community & 0 \\
Alex Ling - Lifetime Achievement & 1 \\
Bricks and Mortar & 4 \\
\hline
\end{tabular}

FIGURE 12: 2015 AWARD SUBMISSIONS BY CATEGORY

The two most distinctly popular award categories were Marketing + Communication, with eight (8) submissions and Special Events + Promotion, with seven (7) submissions. The balance of categories had a limited number of submissions.

These results highlight an important observation in BIA practice, the existing gap between intent and implementation. While the seven award categories determined to reflect best practice clearly align with the principles of community planning and local economic development depicted in FIGURE 4, interest from the field does not follow suit. 
The awards showcase an industry poised to embrace its role in local community development, the submissions paint a slightly different picture. While still presenting a strong interest in economic growth through marketing and event promotion, the submission focus doesn't relay same focus on projects to enhance the social well-being of communities. Both the categories of Business Retention and Expansion and Safe and Healthy Communities received no entries this year.

While only a snap shot of a much broader program, this work signals the need for a more critical analysis on low turnout and suggests a breakdown between intent and implementation somewhere along the way. Reasons may stem from differing industry opinion on the objectives BIAs are empowered to achieve, a disparity in funding across the province, varying levels of engagement and support from the membership and the local council, or apathy toward community initiatives in the general. The need for a more critical analysis of best practice limitations is warranted.

With respect to the influence of planning policies and tools on BIA initiated community development, the awards scan highlights three specific drivers of implementation.

The first is the use of Heritage Conservation Districts (HCDs) to ground BIA-led community development. Collingwood's downtown revitalization efforts offer a case in point on the benefits that HCDs can bring to BIA initiatives. "In 2004, an expansion process was undertaken and a new By-law enacted which increased the original area of the BIA to mirror the downtown core area that has been designated provincially as an historic district" (Town of Collingwood, n.d). With alignment in place, BIA-led downtown revitalization efforts could address the entire heritage district and in reverse, heritage grants available in cases where HCDs are in place, could be utilized by the BIA to implement community focused property improvements.

The second is the impact of legislation, specifically AODA legislation, to enforce accessibility enhancements, and empower BIA Boards to implement the work at the local level. Legislative changes coupled with incentives to entice action offer an ideal climate for BIA-driven community centered projects. Again, using Collingwood's downtown 
revitalization as an example, legislative changes to accessibility requirements across the province brought about changes to both public and private property through the Collingwood Downtown Revitalization Plan, which focused on active transportation, walkable communities, heritage preservation, accessibility (Town of Collingwood, 2015, slide 2). The community focus of the project challenged independent business benefits at times, where patio and retail encroachments were cited as some of the largest barriers to success (Town of Collingwood, 2015, slide 5).

The third is the use of interim by-laws and event permitting to create innovative community spaces within the public realm. The St. Thomas Nostalgia Nights car show highlights the importance of streamlined and flexible municipal approval processes to allow for innovative use of public space within BIA districts. Street closure, interim parking zones, and event and entertainment permitting were all required prior to the event (Downtown Development Board, 2015, slides 5-7). Without flexible controls and a clear approvals process, this important community building initiative may not have taken place. Fostering more than increased revenues for local business, the St. Thomas Nostalgia Nights car show, used a BIA district to generate social and financial capital for the residents and businesses of St. Thomas.

A final note should be made for the importance of grant funding in the implementation of BIA-led community development work - particularly in smaller and rural communities. Access to grant money from municipal, provincial and federal programs was evident in both the Collingwood and the town of St. Thomas initiatives, which allowed for implementation of two successful community-building projects.

\subsection{Key Informant Interviews}

Key informant interview findings outline the perceived capacity of BIAs to implement community-planning practice along with the opportunities and barriers that exist in policy, governance, and context to continue this work. Questions were framed in such a way as to draw out perceptions and opinion on current practice, benefit to both the public and private interest, challenges in implementation and governance, barriers presented in the legislation and access to funding. The culmination of responses allowed for a well- 
rounded perspective on BIAs role in community development and the influence of planning tools on their practice. A copy of the general form of interview questions is attached in Appendix B. A total of seven individual interviews were held with representation from both urban and rural communities, and varying geographical regions across the province.

The results surfacing out of the interviews build on the initial findings unveiled in the award analysis, and help to answer some of the questions raised around existing barriers, low turnout to award best practice, and the urban - rural divide. Appendix $\mathrm{C}$ provides the summary of responses heard through the interview process categorized by question asked.

When asked if BIAs have a role to play in the implementation of local community planning objectives, the interviewees' responses generally agreed that 'yes' their role in community development was important but a lot of uncertainty exists. Varying capacity, understanding, interest and implementation was discussed reiterating the findings from the award analysis. Interviewees felt this variation in practice typically presented itself geographically, where BIAs that exist in larger urban centres tend to be more engaged in community development initiatives than their smaller, more rural counterparts.

In the Toronto context, interviewees felt that the popularity of BIAs was on the rise and place making and strategic planning efforts were cited as a common goal, particularly amongst some of the larger BIAs. Partnerships with the private development sector, elected officials, and academic institutions were considered to have led to a great deal of pilot programming, data mining and research, and foundational broader community planning initiatives in certain districts. These partnerships were all felt to be a positive step forward for BIA programming.

In the broader Ontario context, interviewees felt that the same infrastructure for success did not exist, and there was a lot of "old blood", making it challenging for the BIA concept to broaden and grow. That said, variation exists in the urban-rural divide, where interviewees cited some of the most innovative examples of BIA-led community 
development were coming out of small rural communities like Seaforth, Uxbridge, and Stirling-Rawdon (personal communication, 2015).

Others simply stated that while they anecdotally know of community development initiatives involving BIAs, they had difficulty quantifying benefit to the community without measurable indicators. The lack of consistent data on individual BIAs budgets and performance, the percentage change in the industry across the provincial landscape, and a collective agreement on what indicators to use adds to the general confusion around BIAs impact in local community well being. It also highlights the need for more research in this regard.

One respondent offered a three-phase evolution of BIA objectives as a potential framework for how the industry as a whole can position itself to shift toward greater engagement in community development. The respondent described Phase One as the initial establishment of a BIA where noticeable aesthetic improvements are delivered to the local community. The banners go up, flower boxes are planted, and small jobs are completed to demonstrate where membership levies are going. According to this respondent, phase one is a critical phase in the life of a BIA to demonstrate worth to the memberships, build public acceptance, and municipal reliance on the BIAs efforts. In the terms of this study, phase one reflects the basic contributions of a BIA, it represents the BIA1.0 minimum standard.

Phase Two occurs once the BIA district has been cleaned up and the local membership and surrounding neighbourhood acknowledge the changes in the area. Investments in building facades and streetscaping have been made and the focus shifts to increasing pedestrian traffic and promoting the area as a vibrant and beautiful place to spend time, and spend money. In this phase the BIA can turn its focus to promotion, festivals, markets, and community based events that will attract outside investment into the local community. The second phase of a BIA will work to bring new investment and public recognition from beyond the boundaries of the local community. 
The final phase offers a glimpse at where BIA2.0 could sit. A BIA operating in Phase Three has the support of the local community and its immediate membership. They have also built up a solid local reputation for implementing tactical improvements in the public realm and facilitating community based events. Phase Three represents the point at which BIAs local knowledge benefits the broader public good. With those capabilities in hand, a BIA in Phase Three will expand their capacity as local leaders in strategic long term planning. The focus here is on strategic initiatives, which place small businesses, commercial office and retail land uses as important components of complete communities.

Small businesses are becoming the living rooms and dining rooms of new and intensifying communities around Toronto. We must make sure that we are supporting their existence over the long term through appropriate zoning, tax policy and commercial spaces. (personal communication, 2015).

The delivery of mixed use communities, particularly in areas of change and intensification, requires strategic thinking on how best to attract and retain those uses and deliver sustainable and prosperous places for people to live. BIAs in phase three are able to engage in strategic land use planning, initiate on going community consultation, and build partnerships with private sector development companies and government authorities to ensure the land use zoning, built form spaces, and financial climate all work together to attract the right commercial tenancies over the long term.

Using this as a basis for BIA evolution, there is evidence of BIAs currently operating in phase three, and industry support for this kind of work through recognition of these efforts at the OBIAA annual awards. Yet, most were considered to sit somewhere between phases one and two. In an effort to understand why the variance in BIAs ability to implement community development initiatives across the province, five themes emerged through the interviews, these are discussed below.

\section{Strategic Leadership}

One of the recurring findings throughout the interview process was the importance of progressive attitudes, diplomacy, engagement, open mindedness, and innovation to facilitate BIA success. Animosity created by competing individual business interests and 
short sighted political gains, were found to lead to the demise of a BIA district. From the onset, a BIA organization and its Board must offer leadership, and committed direction in order to combat the repeated challenges of absentee and slum landlords, aggressive and competitive big box retailers, lack of development on vacant land, and storefront vacancies. In each instance, the animosity generated by competing and in some cases independent interests can result in a BIA never taking shape where strong leadership does not exist.

Hesitations around BIA involvement in planning matters were also said to be a result of old practices hanging on in a rapidly changing economic and planning environment. This typically reactive rather than proactive approach to BIA work was thought to be a limitation in advancing BIA practice. The commitment, knowledge and capacity of the local Council, municipal staff and elected officials were also cited as an important factor in furthering BIA practice. A perpetuating perception of municipal opinion on the negligible impact BIA work has on communities, resonated among a number of interviewees. Most felt this attitude the result of a lack of knowledge about what work BIAs are doing, and in turn the lack of existing accurate and quantifiable data to showcase these efforts as the cause. Often times the administrative structure of larger municipalities was thought to be a limitation, where departmental silos resulted in a lack of internal collaboration in municipalities around the benefits of BIAs to the broader community.

\section{Enabling Legislation}

The second is legislation. The interviews revealed the legislative history around BIAs in Ontario to be somewhat negative in its evolution. The reality of BIAs having to function as local Boards of council referred to as a "marriage of convenience" by one respondent (personal communication, 2015). The label of being a 'local board' not something respondents thought BIAs were entirely comfortable with, nor municipalities overly concerned with honouring. In addition, many stated a desire to have the current legislation create a stronger and clearer baseline for good performance. One respondent pointed to the legislation in European jurisdictions like the United Kingdom and Germany as an alternative format, where BIAs were appointed for a fixed term and required to 
demonstrate certain community development benchmarks prior to the renewal of a further term and award of budget. Further examination of these legislative benchmarks would be beneficial for consideration in future legislative changes. For the most part, interviewees felt that BIAs broadly met their responsibilities under the Municipal Act, but didn't typically go above and beyond. The Municipal Act defines BIA responsibilities under Section 204, to include the improvement, beautification and maintenance of municipality owned land, buildings and structures above and beyond the expense of the municipality, and to promote the area as a business or shopping district (2001, s.204). Some interviewees felt that this was a safe place for BIA operators to stay, and that to think outside the box required risk, budget, and a dynamic approach that often wasn't comfortable to local Board members.

Responses also highlighted the varying interpretations of the mandate responsibilities with some BIAs taking the Municipal Act quite literally, and others, typically with larger budgets, having some latitude to explore different aspects of promotion, marketing and advocacy. There was general agreement that there was a broad spectrum of interpretation in the industry on what the "minimum standard" requirements for a BIA are.

Variance between the City of Toronto Act, 2006 objectives and the Municipal Act, 2001 set a different benchmark in the Toronto context than elsewhere in the province. Where COTA specifically outlines BIAs must consider “... strategic planning as necessary to address business improvement area issues" (2006, s.19-3f) and ".... safety and security initiatives" (2006, s.19-3e) and the Municipal Act, 2001 does not. In the interest of a consistent effort toward community development initiatives across the province, clearer alignment of mandate and objectives in the legislation must be made.

\section{Funding and Revenue Sources}

The third theme is funding and revenue sources. The majority of interviewees noted funding grants and incentives as the main implementation tool available to BIAs through municipalities and the province. Funding was repeatedly cited as a major limitation on BIA best practice, and the ability to access alternative revenue streams or one off grant opportunities was critical to the longevity of BIA work. Funding opportunities through the 
province were noted to have decreased over the years, with no funding potential through MMAH and increasingly limited options through OMAFRA. These shifts are consistent with fiscal restraint across all provincial ministries, and not thought to signify any commentary on BIA relevance, but still force BIAs to rely more heavily on levy payments to fund their work. BIAs position as a local Board was again considered to be both a blessing and a curse where funding was concerned. Their organizational definition not qualifying for access to grants that a not-for-profit or charity would, leaving them reliant on the municipal levy or a strategic partnership to secure funding. In many instances, this partnership, with another not for profit or the municipality, had been eroded due to the other themes noted in the findings.

\section{Partnerships}

The fourth theme is partnerships. All respondents agreed that a great working relationship with the municipality is critical to the ongoing success of a BIA. Interviewees noted that there is a lot of dysfunction in practice, and that once important ties with a municipality have been severed, they are often difficult to repair. Interviewees identified the number one trait of a strong BIA as being their ability to communicate. The ability for a BIA to communicate effectively with the municipality, their Council, neighbourhood associations, and the public at large will build a consensus of value and lasting stakeholder relationships. Council support is paramount to furthering BIA initiatives, and many interviewees cited vague and open-ended communication as the biggest problem in gaining that support.

The Board of the BIA should always be working to have a member of council as their new best friend. Cultivating that relationship with Council so that there is a common interest. Every member of council needs to know about BIA (personal communication, 2015).

Partnerships with not-for-profit organizations and municipalities were also seen as critical to unlocking the opportunities for new funding sources. Opportunities to pool financial resources with the municipality were thought to lead to better community outcomes and place BIAs in a more prominent position in the public eye. 


\section{Knowledge and Capacity}

The fifth theme is knowledge and capacity. General perceptions around the capacity of a BIA to delivery broader municipal objectives vary widely. This uncertainty was largely a result of inconsistent performance, lack of adherence to regulatory obligation and cited "in-fighting" between BIA Board members. When asked to identify the characteristics that make a strong BIA interviewees referenced foresight, adventure, creativity and imagination as critical components of a successful organization. A clear recommendation was the needs to put old attitudes aside that perpetuate the "us versus them" mentality, and start building partnerships. Interviewees stressed the need for a soft approach to BIA formation in its infancy - business owners need to see the value, and understand their partnership with other commercial property owners, operators and the municipality prior to agreeing to its formation. These challenges were considered the same across all scales of settlement - neighbourhood, village, town and city, given all deal with the competing interests of individuals to ultimately build a collective.

In smaller communities, interviewees lamented the formation of a BIA is often a tough sell. In some communities there isn't a critical mass of business owners to support the creation and sustained revenue needed for a BIA, or enough capacity at the municipality to support their growth and initiatives. The contextual differences between rural Ontario and larger municipalities are apparent in this discussion, as the recurring limitations to community initiatives were the scale of the commercial precinct, the level of vacancy existing at inception, and the vested interest of the local Council in championing the cause.

\section{Planning Tools}

With respect to the influence of planning tools and processes on BIA work there was general agreement that rarely, if ever, is there a direct link between BIAs and planning departments. With no legislative requirement to participate in the planning process, neither the municipality nor the BIA Board typically reach out to consult on development proposals. With this in mind, the general consensus was that planning tools are not likely used to their full potential in the context of BIA initiatives. Interviewees noted that ideally secondary plans and community improvement plans in locations that encompass BIA 
boundaries could be undertaken in collaboration with the BIA. Recognizing that despite the fact they are not land owners, the do represent the interests and practice of a defined group of land holdings. In addition, friction around the preservation and reuse of heritage properties could be abated where BIAs where involved more intimately with planning around Heritage Conservation Districts and Heritage Act applications.

The varying interpretation of the BIA mandate as described in the Municipal Act, 2001 and its counterpart, City of Toronto Act, 2006 suggest a review of these policies is needed to bring clarity of purpose to the industry. Interviewees suggested changes should be made to further clarify the purpose, and responsibilities of BIAs. One interviewee highlighted the key differences between the two acts being that the City of Toronto Act allows BIAs to make physical improvements to privately owned properties, whereas the Municipal Act mandates that physical improvement must reside in the public realm. Perhaps these two variances should be aligned.

Other suggested improvements to the Municipal Act included clarity and expansion of the mandate to empower the business community to be community builders; consideration of expansion of BIA powers to allow for the ability to own and develop property; limitations on the length of term for BIA Board members; the necessity for an agreement of understanding between Municipalities and BIAs on roles and responsibilities (termed a Memorandum of Understanding); and the addition of legislated reporting requirements between the province and municipalities to track BIA growth or decline and other critical indicators of success.

These differences in practice and policy give reason to pause and ask some important questions on the role BIAs want to play, and the role they are required to play in broader community development. Where interview findings have helped to clarify points of tension in the system, and in some cases proposed recommendations toward relief, the question of what BIAs want to be involved in needs to be asked in tandem with the question of what BIAs should be involved in, to inform a collective advancement to a BIA2.0 framework. 


\subsection{The Planning Toolbox: Scan and Analysis}

The legislative framework for community planning in Ontario establishes the province as the overarching authority on all land use matters, granting delegated authority to municipalities to review and provide approval in a number of cases.

Provincial legislation establishes the benchmark for acceptable practice in all facets of community planning, including planning, development, heritage preservation, environmental practice, and human rights, as well as the ongoing administrative and process matters affecting municipalities, the rights and activities of local municipalities and their Council, along with the appropriate fees and charges for new development.

In addition to legislation at a provincial level, municipalities are required to implement their own Official Plans and zoning by-laws to reflect the policies for growth at a local level. Where a two-tier system is present, as is the case in many parts of the province, both the upper and lower tier government are empowered to implement their own policies reflective of their geographic area. The hierarchical nature of the legislative framework within the province ensures consistency between the policies at all levels of government in an effort to provide clarity and certainty for those operating within the framework.

The Planning Act, 2001 is the key piece of legislation guiding community planning practice across the province of Ontario. This legislation sets out the policies and tools, procedures, timelines and appeal mechanisms to approach growth and development effectively. "In 2007, the principle of sustainable communities was incorporated in the Planning Act through "the promotion of development that is designed to be sustainable, to support public transit and to be oriented to pedestrians" (MMAH, 2009, p.1).

As expressed through the key informant interviews, planning tools are not considered often enough in the efforts to enhance BIA practice at a local level. A lack of awareness of the planning tools that relate to main street revitalization and small scale commercial business, along with varied capacity to administer what is available, has left planners, economic development officers and BIA executive operating without the full benefit of existing legislated controls and incentives. 
The chart outlined in FIGURE 13 reflects the breadth of planning tools embedded in the community planning framework that are considered to influence the work of BIAs. The chart identifies current influence and indicates if the potential for future involvement from BIA Boards is 'direct' or 'indirect'. Where 'direct' input means there is an opportunity for BIA Boards to be more specifically engaged by the tool or directly involved in its use, for example, mandatory engagement in a Zoning By-Law application would constitute direct input. 'Indirect' input indicates a tool that will continue to influence BIA practice with BIA Boards providing voluntary and/or secondary input into their use toward BIA initiatives.

\begin{tabular}{|c|c|c|c|c|c|c|c|c|}
\hline \multirow{3}{*}{\begin{tabular}{|l|}
$\begin{array}{l}\text { Provincial } \\
\text { Legislation }\end{array}$ \\
Heritage Act
\end{tabular}} & \multirow{2}{*}{\multicolumn{3}{|c|}{ Planning Policies and Tool }} & \multirow{3}{*}{ 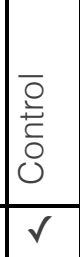 } & \multirow{3}{*}{ 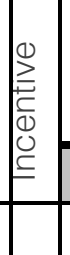 } & \multicolumn{2}{|c|}{$\begin{array}{l}\text { Current } \\
\text { Influence }\end{array}$} & \multirow{3}{*}{$\begin{array}{l}\text { BIA2.0 } \\
\text { input? }\end{array}$} \\
\hline & & & & & & + & & \\
\hline & & $\overline{\mathrm{HCD}}$ & & & & $\checkmark$ & & \\
\hline \multirow{6}{*}{ Planning Act } & \multirow{6}{*}{ PPS } & \multirow{3}{*}{ Official Plan } & $\begin{array}{l}\text { Secondary } \\
\text { Plan }\end{array}$ & $\checkmark$ & & $\checkmark$ & & Direct \\
\hline & & & $\begin{array}{c}\text { Transit } \\
\text { Oriented } \\
\text { Development } \\
\text { Plans }\end{array}$ & $\checkmark$ & & $\checkmark$ & & Direct \\
\hline & & & $\begin{array}{c}\text { Design } \\
\text { Guidelines }\end{array}$ & $\checkmark$ & & $\checkmark$ & & Direct \\
\hline & & Zoning By-Law & $\begin{array}{l}\text { Density } \\
\text { Bonusing }\end{array}$ & $\checkmark$ & & $\checkmark$ & $\checkmark$ & Direct \\
\hline & & $\begin{array}{c}\text { Community } \\
\text { Improvement Plan }\end{array}$ & & $\checkmark$ & & $\checkmark$ & & Direct \\
\hline & & $\begin{array}{l}\text { Development } \\
\text { Permit System }\end{array}$ & & $\checkmark$ & & & & Direct \\
\hline $\begin{array}{l}\text { Development } \\
\text { Charges Act }\end{array}$ & & $\begin{array}{l}\text { Development } \\
\text { Charges }\end{array}$ & & $\checkmark$ & $\checkmark$ & $\checkmark$ & & Indirect \\
\hline Municipal Act & $\begin{array}{c}\text { S 204- } \\
215,216\end{array}$ & & & $\checkmark$ & & $\checkmark$ & $\checkmark$ & Direct \\
\hline $\begin{array}{c}\text { City of Toronto } \\
\text { Act }\end{array}$ & Ch. 19 & & & $\checkmark$ & & $\checkmark$ & $\checkmark$ & Direct \\
\hline
\end{tabular}

FIGURE 13: PLANNING TOOLS IMPACTING BIAS IN THE ONTARIO PLANNING SYSTEM 
Those tools considered most applicable to a BIAs scope of work are shown in FIGURE 14 and analyzed in greater detail below, with consideration of their current influence on BIA practice and potential for enhancements in the future. While the forthcoming policy analysis is largely drawn from the investigator's own knowledge base, feedback from the awards analysis and key informant interviews helped to identify the refined list of tools for analysis, and guide the determination of their influence. A broader summary of the full range of planning tools identified in FIGURE 13 is provided in Appendix E.

The proceeding evaluation of planning tools is based on a multi-dimensional matrix that allows for consideration of both the form and impact of influence each planning tool is having on current BIA practice. FIGURE 14 depicts this relationship, where the vertical axis reflects whether the tool is a 'control' or an 'incentive' and the horizontal axis reflects the tools influence as either 'positive' or 'negative'. Given the exploratory nature of this research and its qualitative assessment of influence, the matrix allows for a general determination of influence toward one axis or another in order to indicate a trend rather than reflect quantitated findings.

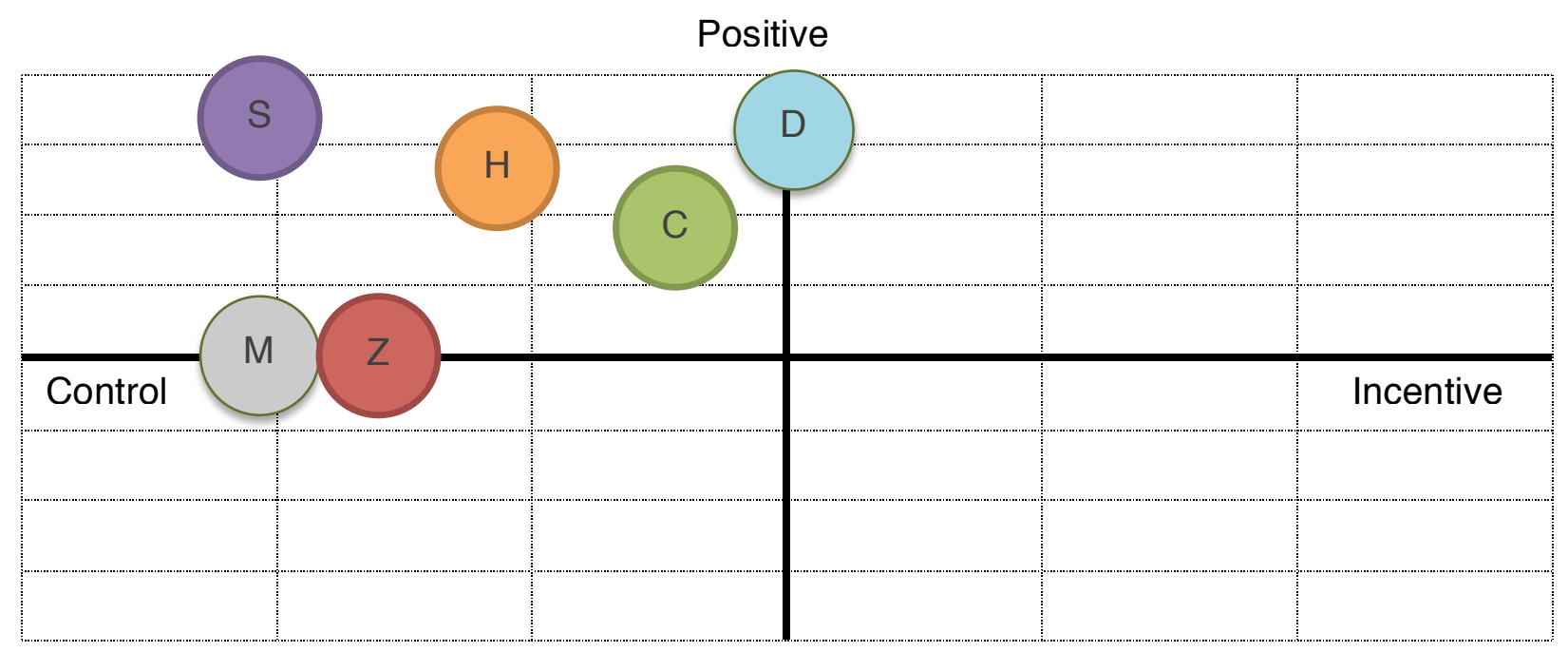

Negative

Figure 14: Planning ToOl Influence Matrix 


\section{Secondary Plans (SPs). Transit Oriented Development Plans (TODs)}

Working in concert with the Official Plan, these localized policy documents shape the growth of specifically defined areas of a municipality, Typically focused in areas with high pedestrian and vehicle traffic, and anticipated growth or development pressure, the secondary planning process (which includes TOD Plans) allows for a finer grain examination of the land use concepts most appropriately suited to a certain location. Their intersection with BIA practice made clear where most include a node or corridor with a high commercial component and at times coinciding or overlapping with an existing defined BIA precinct.

\section{Analysis}

As part of an overarching policy framework for future development, secondary plans and transit oriented development plans are considered to have a positive controlling influence over the work of BIAs as they establish locations for and amount of commercial land use. In effect, these plans help to forecast the potential future locations of BIAs. Yet generally, BIAs do not hold a formal role in the creation of these plans outside of the regulated public consultation process which allows for citizen input. Where possible, municipalities and BIAs alike would be well served to engage the local BIAs knowledge and opinion and undertake preliminary commercial analysis for the area. In order for mixed land use areas to succeed they require the appropriate balance of residential and and employment opportunity, along with the right mix of commercial, retail, social and transit services to be successful. Proactive commercial analysis and engagement with the broader business community would allow for the plan to reflect the needs of the market and encourage development of residential and complimentary commercial uses simultaneously.

For example, the Richmond Road/Westboro Secondary Plan in Ottawa, Ontario promotes development of new retail and small business opportunity through its secondary plan policies. It also encourages the redevelopment of land that currently has 
less complimentary uses within Westboro Village. Both of these directions have important implications for the local BIA activity. One such policy reads:

Encourage mixed use, including a continuity of ground floor retail/restaurant uses with residential and office uses on the upper floors. Car sales lots and other automobile-oriented uses should be redeveloped with active traditional main street pedestrian-friendly uses. (Ottawa, 2009, p/6)

Specific to Transit-Oriented-Development the incentive for BIA engagement is huge. Where a municipality has established the requirement for area specific plans adjacent transportation stations and corridors, the need to effectively plan and locate commercial uses to create functional intensification is critical for both planners, and business owners. In particular, the ability to understand the balance of needs between the varying forms of retail and commercial uses- large format retail, office space, co-working options and/or independent storefronts - will assist municipalities in delivering on TOD principles and ensuring vibrant and active spaces.

\section{Community Improvement Plans (CIPs) (Planning Act, s.28)}

A planning tool used to revitalize a defined geographical area as approved by Council. CIPs allow for municipalities to direct funding and development efforts in a meaningful way to encourage "...land assembly and clearance, infrastructure provision and public space improvements" (MMAH, 2009, p. 2). In addition, they often have the ability to unlock funding or grant programs toward private sector development investment, such as brownfield assessment, greyfield adaptive reuse, and heritage rehabilitation. MMAH (2009) also highlights the benefits of leveraging CIP creation to encourage improved housing and transportation infrastructure along with inter-municipal intensification strategies (p.2).

\section{Analysis}

Completion of a Community Improvement Plan (CIP) allows municipalities to direct funding potential in the form of incentives, grants and/or tax relief to a particular area. In this respect it is considered a positive control in that its creation unlocks the ability to access positive financial and regulatory incentives for development. This tool can be 
utilized in both large and small communities to identify a certain geographical area for focused improvement.

In the City of Hamilton, all 13 BIAs are included in a municipal CIP to allow for improvements across each designated commercial precinct. The implementation of this planning tool has been coupled with a comprehensive program of data collection to gather BIA specific market analysis and understand the context of each precinct (OBIAA conference, 2015).

\section{H Heritage Conservation Districts (HCDs) (Heritage Conservation Act,Part V)}

A planning tool used to establish the heritage significance of a defined geographical area, the HCD is a designation under Part $V$ of the Heritage Act, and once in place establishes the requirement for additional development applications and approval under both the Heritage Act and the Planning Act on future development proposals. Typically, a municipality's official plan will have specific policies relating to development restrictions within an HCD, and accompanying set of heritage design guidelines outlines built form restrictions on any property within its boundary.

\section{Analysis}

The implementation of a heritage conservation district recognizes both an importance and concern for historic places within local communities. Community heritage is predominantly defined at the local level with an areas heritage context preserved through the stories and experiences of local residents, and the retention of buildings and public spaces over time. Increased development pressure, aging infrastructure and constant property maintenance demands all threaten to erode the vitality of heritage districts without stewardship and appropriate protection mechanisms. HCDs offer a mechanism to control new development, direct investment, and preserve a certain design aesthetic within designated areas. There is a symbiotic relationship between the intent of BIAs and HCDs. While BIAs may define a variety of commercial precincts, their roots are based in traditional mainstreets and downtowns across the province. Often times, the BIA district embodies the cultural landscape of a community. This connection to heritage 
is typically centered on the preservation of traditional small business retail and the protection of a defined place within local communities. In the same respect, the challenges that exist in adapting the use of heritage buildings for modern business can sometimes limit the commercial opportunity of certain properties - this in turn could make the influence of HCDs over BIA practice seem negative. Where the challenge of heritage preservation may pose barriers for the individual property owner, the intent of HCDs to preserve a community's cultural landscape is considered a positive control for BIAs. Municipalities may tie certain funding opportunities, including building façade improvement grants, and tax relief, to the HCD designation.

The use of HCDs and BIAs in three of the villages that originally existed around what is now the larger Mississauga metropolitan area, offer a great example of how the planning tool (HCD) and the BIA concept work together to protect and enhance community identity. The villages of Streetsville, Port Credit and Clarkson have been able to retain their unique identities amidst rapid urban development and population growth in the Mississauga, Burlington corridor. The retention of these unique identities has given many Mississauga residents to create a local connection to the historic landscape of the region, and a sense of place (personal communication, 2015).

\section{z Zoning By-Law (Planning Act, s.34):}

Zoning By-Laws regulate the built environment in urban and rural settings with the aim of achieving sustainable community design and creating safe, and vibrant places to live. Provisions are outlined to control land use type and location, yard setbacks, height and density restrictions. They also allocate minimum and/or maximum parking provisions and servicing standards. They can be initiated on a site specific or corridor/area wide geography, which causes the sphere of influence to vary considerably.

\section{Analysis}

Zoning By-Laws can have huge implications for potential uses along a commercial mainstreet. They are considered to be both a positive and a negative control in the land use policy framework influencing BIA success. 
Commercial mainstreets and downtowns are a complicated mix of uses. The ability for them to thrive and remain relevant requires active commercial frontages, an appropriate mix of uses and commercial tenancy that meets the needs of the local population.

As a positive control, zoning has the potential to influence the type and form of commercial office and retail space within a core commercial area. The City of London for example, has specific zoning for their Downtown Area with variations in regulation that "...emphasize the pedestrian-oriented shopping area and to regulate the scale of retail permitted" (City of London, n.d, Section 20,policy 20.1).

As a negative control, zoning can inhibit commercial activity through restrictions on parking, use of outdoor space, and right of way encroachments. Where amendment to zoning regulations are required, additional applications are necessary to amend the standard through minor variance. This places onus on the property owner or commercial tenant to submit applications through the Committee of Adjustment, which are subject to panel review and public appeal. Where a municipality has initiated a Zoning By-Law review in areas of revitalization and commercial focus, opportunities to undertake a detailed review of zoning standards with the local BIA should be initiated in the interest of attracting and retaining small business.

Further analysis of the impact multiple zoning amendments within a BIA district would have on BIA districts in the Toronto context was explored by TABIA and Neptis group with insightful conclusion. Where the City of Toronto's Official Plan (OP) designates land along its "Avenues "as mixed use to "[...] encourage a broad range of commercial, residential, institutional and open space uses" (City of Toronto, 2010), and the provincial Growth Plan encourages mixed-use development as a sustainable form of growth. The planning intent to promote a wide variety of compatible uses along commercial mainstreets can at times result in the slow erosion of established concentrated commercial corridors, with alternative and perhaps compatible uses. New development pressure in established areas can have the affect of interrupting the rhythm of the initial commercial strip and deter patronage. TABIA cites the challenge of multiple zoning by- 
law amendments within Business Improvement Areas as a critical issue in the erosion of neighbourhood retail.

Neptis on the other hand, had a broader frame of reference when examining commercial patterns in the Toronto region. Their report entitled Places to Shop, Places to Grow discussed the continued intensity of neighbourhood retail in Toronto's core throughout the period 1995-2006 despite the otherwise clear shift of retail to suburban power centres and auto dependent shopping (Neptis, 2009). Neptis (2009) suggests that the continued demand for small business retail space in Toronto's core may be simply be a reflection of the fact that space is available, given newer suburban commercial centres are zoned with provisions geared toward larger format retail use.

\section{Development Charges (DCs) (Development Charges Act, 1997, Part II)}

The Development Charges Act, 1997 was established to legislate municipalities' ability to request payment from developers for the cost of new infrastructure as a result of development activity. Based on the premise that growth pays for growth, development charges (DCs) cover the costs associated with new infrastructure services, such as roads, water and wastewater, transit and libraries (MMAH, n.d.). DCs are only used to finance growth related capital costs, and cannot be used by municipalities to fund other programs or infrastructure repair

\section{Analysis}

The payment of development charges on approval of a project is often a significant cost outlay in the development proforma. The opportunities for BIAs to benefit from this contribution to infrastructure improvements are two fold - both are positive, one acts as a control, the other an incentive. As a positive control, DCs offer a significant source of revenue for municipalities and potentially BIAs in the interest of construction new infrastructure services. Traditionally, this revenue stream has been earmarked for investment in growth related infrastructure. The Development Charges Act, 1997 states that: 
2. (1) The council of a municipality may by by-law impose development charges against land to pay for increased capital costs required because of increased needs for services arising from development of the area to which the by-law applies. (c. 27 , s. 2 (1)).

It goes on to define what applications the term 'increased need for services' relates to, and what services are ineligible in Part II, sections 2 and 4 below:

\begin{tabular}{ll}
\hline Applications DCs Apply To & Ineligible Services \\
(DC Act, 1997, Part II s.2) & (DC Act, 1997, Part II s.4) \\
\hline Zoning By-Law & Cultural/entertainment Facilities \\
Plan of Subdivision & Tourism facilities \\
Minor Variance & Acquisition of land for parks \\
Consent & Hospital \\
Condominium & Waste Management Facilities \\
Permit under the Building Code & Municipal Headquarters \\
Conveyance of Land & Other Services prescribed in regulations \\
\hline
\end{tabular}

Recognition of the growth occurring as a result of infill and intensification must resonate with the application of these fees by municipalities. Consideration of re-investment back into established and growing neighbourhoods may be something that municipalities should consider to address the changing nature of how and where people chose to live. In the interest of creating complete communities, investment in infrastructure where growth is most intense is a sound approach. The limitations imposed by reference to "new infrastructure" are worthy of review in the next comprehensive review of the Act. The opportunity for municipalities to consider DC investment back into established urban environments would provide a vehicle to implement the downtown and mainstreet revitalization efforts. Development charges could then be used toward new infrastructure within defined BIA districts in areas where growth can be quantified. Infrastructure such as new sidewalks, improved lighting, and digital and municipal servicing which address safety, accessibility and economic development objectives, would be supported. While this use of development charges is currently not contemplated under the Act, it is worthy of consideration as a potential source of additional funding. 
As a positive incentive, municipalities can offer reductions or exemptions to development charges along commercial corridors in an effort to stimulate investment and new construction. (MMAH, 2008) Alternatively, BIAs can work with municipalities to encourage density and residential growth adjacent to a commercial district through development charge exemptions in order to stimulate residential and in turn economic growth. An example of this is in the City of Ottawa where the municipality "[...] focused on small scale investments in the downtown, primarily through the waiving of development charges that helped the City see $\$ 235 \mathrm{M}$ in residential growth between 2002 and 2011." (CUI, 2013) The opportunities to leverage development charges as a potential funding mechanism for improved infrastructure and an incentive for new development in and around mainstreets and downtowns are worthy of continued use and exploration.

\section{$\mathrm{M}$}

\section{Municipal Act, 2001 and City of Toronto Act, 2006 (MATA) Alignment.}

The Municipal Act, 2001 is the core piece of legislation guiding the establishment and function of Business Improvement Areas across the province. It defines both the mandate and processes for establishing and operating a BIA as well as the appropriate mechanism to determine a levy within the province of Ontario. Bill 130 was passed in 2006, implemented a number of significant changes to the Act that had impact on the functional relationship between BIAs, municipalities and the province, namely the introduction of Section 216, which outlined municipal powers over local Boards. This section allows municipalities to dissolve or change local boards, of which BIA Boards are a part, and ensure BIA Boards themselves, retain the ability to collect the mandated levy (personal communication, 2015). At this time of this study, the Municipal Act, 2001 along with its counterpart legislation the City of Toronto Act, 2006 are both under review by the Ministry of Municipal Affairs and Housing.

\section{Analysis}

A review of the BIA mandate listed under Sections 204 (1) and 19-3 in each piece of legislation provides a clearer picture of the spectrum of work BIAs are required to undertake. 
Municipal Act, 2001

Section 204 (1) - BIA

Mandate

\author{
City of Toronto Act \\ Section 19-3 - BIA Mandate
}

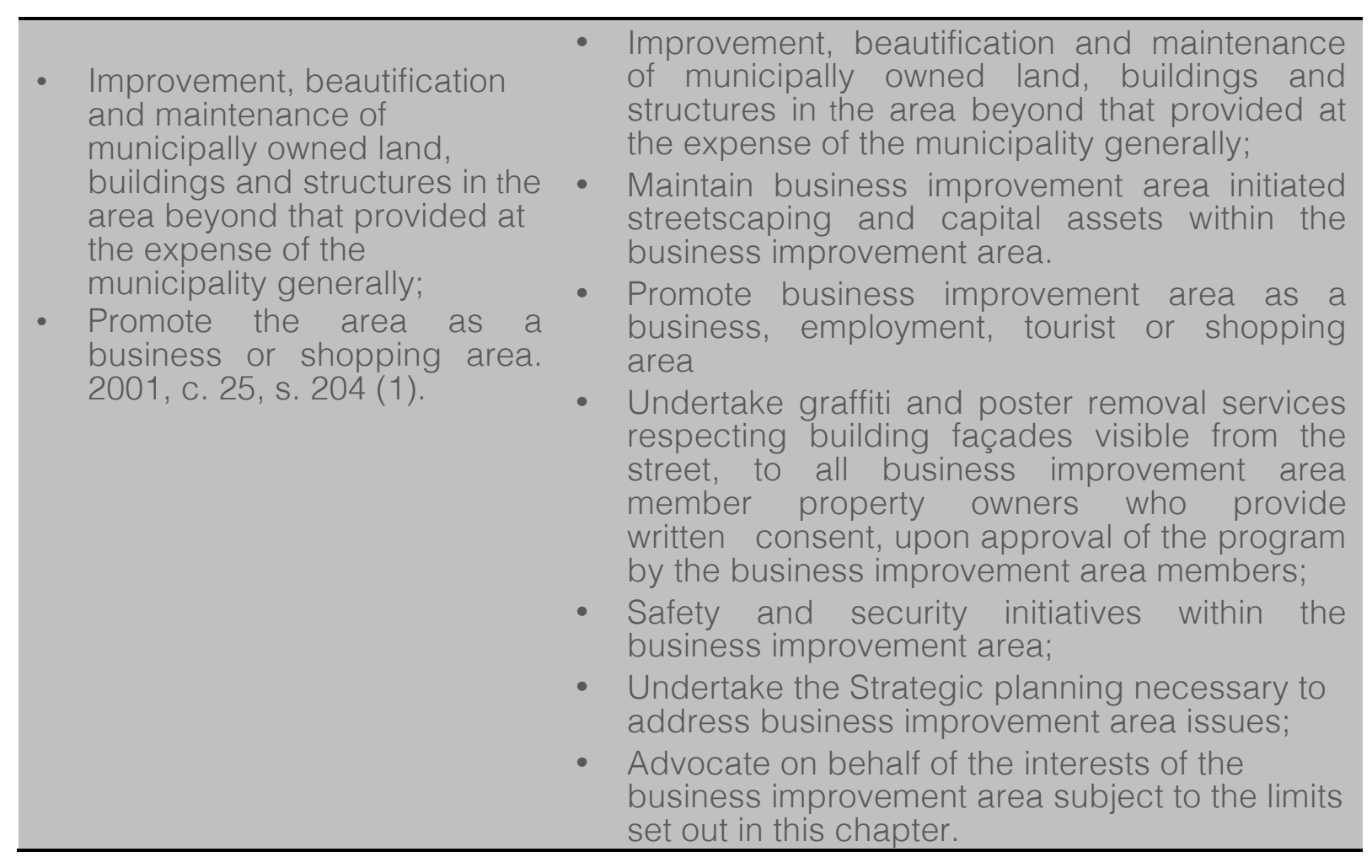

The City of Toronto Act, 2006 offers a substantially more evolved list of objectives for BIA Boards to deliver on. This discrepancy in legislated responsibilities undoubtedly plays out in practice. The award winning case study analysis highlights the pre-dominance of Toronto based BIA efforts in community development, and interview insights recognize the legislation as a benchmark for practice and reiterate the range of BIA approaches to community development across the province. The City of Toronto Act, 2006 under Section 19-3 specifically has two policy objectives related to community development above and beyond those already outlined in the Municipal Act, being:

e) To undertake safety and security initiatives within the business improvement area;

f) To undertake strategic planning necessary to address business improvement area issues. 
The addition of these two objectives in Section 204 (1) of the Municipal Act would provide clarity to the industry and establish a consistent benchmark for BIA performance and evaluation.

Section 204 (3) outlines the BIA board of management and their membership. The composition of the board of management is considered to be a critical element of each BIAs success. The Municipal Act does very little to encourage BIA collaboration with surrounding local residents or established resident associations, and as such is considered to be a negative control. The gap in required notification and communication with the surrounding community appears to be an oversight from both a local economic development and community planning perspective. Endorsement of BIA initiatives from local residents would encourage support and a guaranteed consumer base from neighbouring residents. Engagement with the local community would provide the BIA Board with insight into local commercial and service needs to better equip the Board to meet those demands. This collaboration could lead to new business opportunities, and create a supportive and self-sufficient local economic system. Inclusion of a local community member on the BIA board of management may provide a needed connection between the BIA and the local community.

Historically, section 216 was added to the Municipal Act in 2006 in an effort to find compromise between a general municipal interest in removing the BIA section of the Act entirely, and the industry's interest in maintaining it (personal communication, 2015). The interview findings suggest that Section 216 was added to provide both flexibility and clarity around the municipalities' authority over BIA operations. Interviewees also suggest that very few municipalities are utilizing the powers granted by this regulation to adopt context specific municipal By-Laws around the practice and role of BIAs in local communities. Recognizing the limits of provincial legislation to offer context specific direction, Section 216 grants municipalities with the right to pass By-Laws directly related to their community and the BIAs role within it and act as positive control.

From a BIAs perspective, the By-Law could be used to establish processes, roles and responsibilities for both the BIA Board and the local municipality to give clarity and 
comfort on operational matters moving forward where interview findings suggest the need for an MOU, an alternative that exists in legislation could be clarity of roles through By-Law. Other processes including permitting could also be given special priority in BIA districts under By-Law. Further exploration of the opportunities presented to both municipalities and BIAs by Section 216 is warranted.

Section 364 outlines the potential for vacancy rebates on commercial properties within a designated Business Improvement Area. Where, "Every local municipality shall have a program to provide tax rebates to owners of property that has vacant portions if that property is in any of the commercial classes or industrial classes, as defined in subsection 308 (1). 2001, c. 25, s. " (s. 364(1)).

Interview findings suggest that the rebate on vacant property is a disincentive to encourage commercial tenancy in areas of economic hardship. While the premise of the rebate is to ensure that property owners and small business owners are not out of pocket when the market turns, in practice it is leading to a number of cases where properties sit vacant for quite some time, given the rebate kick back provided. In this case, it operates as a negative incentive toward revitalization efforts and tax revenue. The inclusion of a bonusing structure or receipt of some form of tax relief may encourage property owners to retain or obtain new commercial tenancy and help keep vacancy rates low along mainstreets. This kind of amendment would still protect small business owners from levy payments during a market downturn, but encourage efforts to secure tenants and create active storefronts and vibrant street life.

\section{Insights}

The policy review highlights ways in which priority planning tools influence BIA practice, and suggest areas for improvement to entrench community development in BIA objectives and improve day-to-day operation. All of the tools studied exist within the positive control quadrant. With zoning by-laws and both the Municipal Act, 2001 and City of Toronto Act, 2006 considered neutral in terms of impact of influence (having both positive and negative influence over the work of BIAs) and Development Charges being 
considered the closest to an incentive for BIA practice where used to stimulate investment in downtown precincts.

The gap in incentive based policy is notable, and the creation of more incentive based policy to encourage community development initiatives in BIA practice worthy of consideration by municipalities.

\subsection{Identifying the Shift: A summary of findings}

Common threads have emerged from each component of the research study, and offered insight into the ways in which planning tools are used in the field. In consideration of the role BIAs are fulfilling in community development practice both the award analysis and interview findings present clear evidence that there are many BIAs currently playing an active role in implementing broader community development objectives within their designated areas. The award winners showcase on-the-ground examples of BIA-led public initiatives that reach beyond the independent business owner. The interview observations lend weight to this evidence.

Yet, there is a broad spectrum of community-focused practice and understanding in the field. The award and interview findings highlight variations in ability, interest and knowledge toward community development practice, both in geography and in scale. While the award winning trends indicate a focus of best practice in Toronto and the southwest it is also observed that this geography is tied to the more populous settlement areas in the province. The question then becomes, is the difference a result of regional support, scale of municipality, or entirely localized and contextual? Given the trend of award submissions over the past four years, regional trends are assumed to link to the relative size of local municipalities in their area, with BIAs in larger urban municipalities evidently promoting a focus on community development practice more than others. Yet, despite this overarching trend toward BIA community development in urban contexts, there remains variation across the spectrum. For this reason, we must look to a more localized and contextual reasoning. As the interview findings suggest, to divide BIA practice on urban and rural geographies would not accurately reflect the findings 
gathered. Award winning efforts in smaller and rural communities also exist. Interview insights verify these observations through other cited examples in the field.

Uncertainty around a BIAs influence and role in fostering community well being remained constant throughout the interview process. Differing perspectives came as a result of personal interpretation of legislated requirements, and a lack of quantifiable indicators and data to confirm BIA impact in local community development practice. Beyond establishing benchmarks and quantifying impact, the interviews highlighted a number of common factors that influence BIAs role in community development. The importance of strong leadership, collaborative Board members, appropriate and clear legislation, secure funding, relationship building, and internal capacity were outlined as core determinants of BIA success.

The research findings reflect the breadth of scope that BIAs across Ontario have extending from independent business interests to strategic community development. These elements at their most basic are not silo functions of a BIA Board, but instead help to frame the spectrum of BIA practice. The progression toward BIA involvement in strategic community development was suggested in a three-phase evolution, with community based projects celebrated as a best practice achievement through recognition at the OBIAA awards. In placing these three phases against the elements of responsibility, a spectrum of practice beings to take shape. Overlaying the identified determinants of success further enhances our understanding of the factors influencing a BIAs position on this spectrum. FIGURE 19 visualizes the spectrum of practice for BIAs. 


\section{Strategic Enabling \\ Leadership Legislation \\ Funding Partnership \\ Capacity}

Independent

Strategic Community

Business Interest

Building

\section{Phase 1}

Phase 2

Phase 3

\section{BIA1.0}

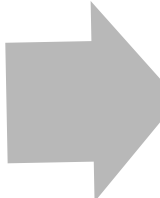

\section{BIA2.0}

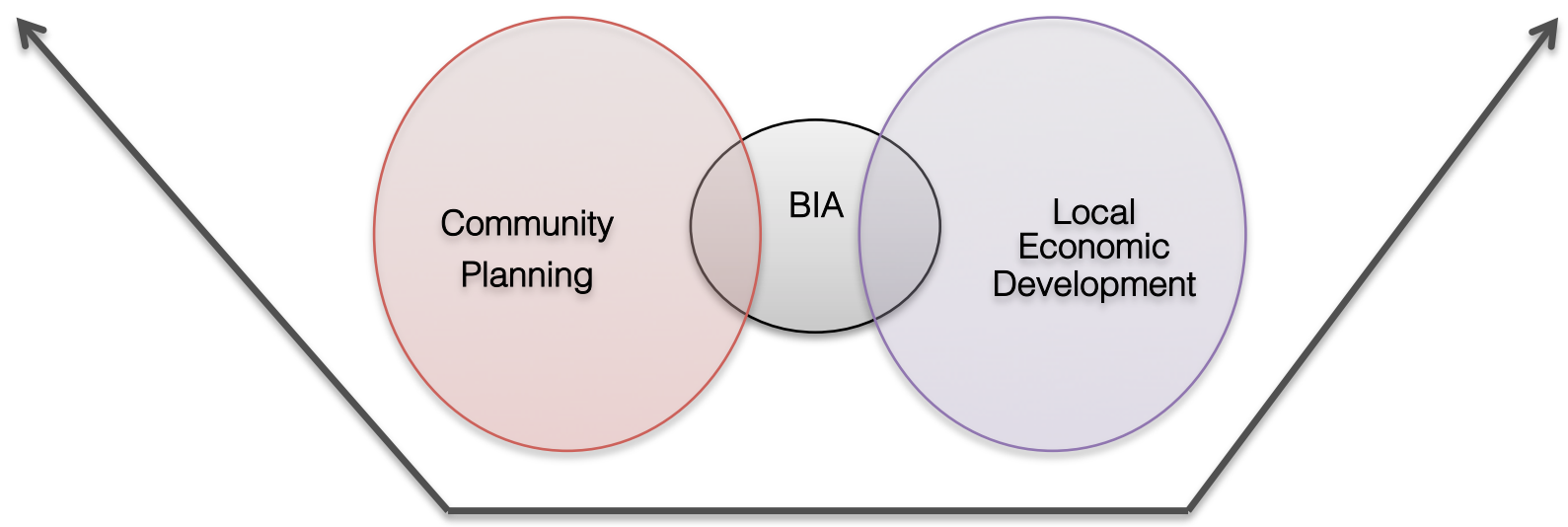

FIGURE 15: BIA SPECTRUM OF Practice

There is a clear need for greater understanding around the opportunities that already exist within the policy framework and the benefits each tool presents. Collaboration between community planning, local economic development, and BIA professionals would work to address this knowledge gap. It is important for BIA Board members to recognize the relevance of planning tools in their scope of work, and where they can have direct or indirect input to future use. FIGURE 13 helps to outline these relationships. 
The policy scan offered clarity around linkages between planning tools and BIA project implementation. Where some tools are clearly utilized in current practice, others have not been explored to their full potential. The inclusion of certain planning tools along this spectrum should always work to accelerate the advancement of BIA practice where based in the public interest. Certain tools have demonstrated their ability to assist BIAs in practice and accelerate their community development initiatives. The gap in incentive based policy is notable, and the creation of more incentive based policy to encourage community development initiatives in BIA practice should be considered by municipalities. 


\subsection{Trending Toward BIA2.0}

Sustainable community planning calls on policy makers and practioners alike to make better use of the existing resources available to them to maximize community potential. As cited in Roseland (2000), Wachtel (1989) observes that the key to a sustainable future lies not in making us more competitive but rather in making us more perceptive, more able to realize what we have, what we need, and what are the long-term consequences of the short-term choices we are making (2000, p.126).

This message resonates in the findings of this study. In principle, policy and practice there is clear evidence that BIAs hold social capital and market knowledge in their local community. They are also positioned at the intersection of local community planning and economic development objectives. In this position, they have an important role to play in fostering a shift toward more cohesive, integrated and community focused cities and neighbourhoods that can adapt to the continuous change of our lived environments.

The BIA has proven to be a unique relationship shared between municipalities and business owners, with benefit to both sides if fostered successfully. The rare opportunity for municipalities to harness entrepreneurial spirit through legislation should enable delivery of localized and impactful community objectives. While the dedicated funding guaranteed through a municipal levy, provides business owners access to money for area enhancements that can benefit both the community at large and independent business revenues.

Municipalities, elected officials, BIA executive and small business owners alike must recognize, foster and respect their responsibility toward community building, in order to be impactful. BIAs offer planning practioners and policy makers a direct link to the mechanics of grass roots community based entrepreneurship and a local understanding of community needs. This link should be leveraged to implement the objectives and targets so tirelessly planned for by municipalities and regions across the province. 


\subsection{Recommendations and Conclusions}

This study highlights best practice BIA work, its link to community planning objectives, and the challenges surrounding its delivery. In looking at the evolution of BIAs engagement in local community planning, recommendations to advance a BIA2.0 agenda are focused on fine tuning the understanding of BIAs role in local communities, and enhancing the use of planning tools in their practice. Recommendations are based on the five key components emerging from the research, and the review of planning tools influence and inclusion of BIAs.

\section{Strategic Leadership:}

1) OBIAA are encouraged to work with TABIA and their collective membership to define a collective vision for Business Improvement Areas across the province. The creation of a BIA2.0 agenda would provide a collective mission statement and address the commitment to their position at the intersection of local community planning and economic development.

2) OBIAA and TABIA are encouraged to find partner organizations to commission a study to establish clear indicators of the impact BIAs have on communities. Using best practice examples from other global jurisdictions and various indicator series employed by the City of Toronto, the City of Burlington, and other areas of the province, the study would engage the BIA membership and municipal staff to provide a comprehensive set of indicators on BIA performance. Once the benchmark is established, data can be collected annually and performance measured.

3) MMAH are encouraged to work with the Federation of Canadian Municipalities and Association of Municipal Clerks, Treasurers and Officers to clarify the terms of employment for hired BIA staff.

4) OBIAA must work with its membership to create a province wide standard for BIAs and/or their staff in order to improve staff retention and BIA board accountability. 


\section{Enabling Legislation:}

5) The province must to update the Municipal Act, 2001 and City of Toronto Act, 2006 to reflect a refined and collective mandate for BIAs, which legislates a consistent level of responsibility in communities large and small.

6) MMAH is encouraged to consider the following amendments to the Municipal Act, 2001:

a. Align the mandate for BIAs under both the Municipal Act, 2001 (204(1)) and City of Toronto Act, 2006 (chapter 19-3).

b. Amend section 207(1) to require municipalities to report annually on the establishment, dissolution, and performance of BIAs to the province.

c. Amend section 204(10) to limit the number of terms for Board members to allow for new representation.

d. Amend section 204(3) to require the inclusion of one (1) community member as part of any BIA Board or at least mandate consultation with community associations prior to project initiation.

e. Encourage the use of Municipal Act section 216, or the creation of an MOU to clearly delineate roles and responsibilities with the province.

f. Consider amendment to section 364(1-25) to deter commercial vacancies.

\section{Partnership:}

7) OBIAA and TABIA must find ways to encourage BIAs to build bridges with their local municipality and foster partnerships. Possible incentives could be a small annual grant, free tickets to the national conference, a specific award dedicated to a 'municipal- BIA partnership initiative'

8) OBIAA and TABIA are encouraged to partner with the province and elevate their awareness campaign in order to educate municipalities and elected officials on the benefits of BIAs in Ontario. Engagement with the Federation of Canadian Municipalities, or the Association of Municipal Clerks, Treasurers and Officers is encouraged.

9) OBIAA are encouraged to partner with OMAFRA's regional economic development officers in order to focus on membership engagement in the North and East regions to respond to low turnout at the annual awards. 


\section{Funding and Revenue Sources:}

10) OBIAA are encouraged to explore opportunities for greater external funding through partnership, incorporation, or the use of existing planning implementation tools such as Development Charges or Community Improvement Plan incentives. A more directed study on the enhancement of specific planning tools to leverage BIAs influence is recommended. With respect to the use of Development Charges within BIA districts, MMAH are encouraged to give broad consideration to the current use of DCs toward growth, and their ability to provide additional funds in intensifying neighbourhoods in future.

\section{Knowledge and Capacity:}

11) TABIA and OBIAA are encouraged to create a shared committee of best practice. This committee would use the knowledge of existing exemplary BIA work to educate the broader membership on advancing industry standards. Consideration of this "Pay it Forward campaign" would build capacity from the inside out.

12) TABIA and OBIAA are encouraged to consider a "BIA big brothers and sisters" program to align experienced BIAs with newly formed BIAs to facilitate knowledge sharing and capacity building amongst the broader membership.

Advancing the influence of planning tools on BIA practice requires consideration of the following amendments and advances within the current framework.

13) OBIAA and TABIA are encouraged to work with local municipalities to consider the following recommendations to improve BIA access to municipal level planning policies and tools:

a. Mandate the requirement for a retail assessment and strategy as part of the list of required studies associated with any of the following applications: CIP, DPS, OPA.

b. Mandate consultation with BIAs where a development application falls within the defined district or within $120 \mathrm{~m}$ of the boundary. 
14) OBIAA and TABIA are encouraged to engage their membership to complete an asset map of existing community capital with each BIA district to understand strengths, weaknesses, opportunities, and costs. These asset maps would bring together a broader regional dataset to ultimately built physical, natural, cultural and social wealth holistically. 


\subsection{Future Research}

Throughout the course of this work, a number of areas for further exploration became evident. The most critical being a collective vision for BIAs on the spectrum of practice (FIGURE 15). The limitations of this study don't allow for further examination of the industry's desired position, but the findings presented clearly suggest the importance of this work to advance a progressive BIA2.0 practice. Using the three-phase evolution as a guide, industry review of benchmark objectives and activities within each phase would also help to secure BIA input into various components of the planning framework. A more detailed analysis of the planning tools available to BIAs could then be completed.

Beyond clarity of purpose, further work should be done to establish a set of indicators to quantify the relevance and success of BIA work. Data and performance tracking will inform both the BIA membership and the broader community to improve the public understanding and appreciation of the role BIAs can play in their local community. Once industry consensus on the role of BIAs in local communities is reached, and set of measurable indicators in place, then a benchmark exercise can be completed to establish each BIAs position within the overarching spectrum. This type of evaluation could assist in the advancement of current BIA practice through enhanced collective understanding and measurable success.

Consideration of BIA global practice and potential legislation to encourage BIA board and/or staff certification should also be completed to address the challenges of staff retention and perceptions of BIA legitimacy.

Finally, a more detailed analysis of specific planning tools and their ability to assist BIAs in the implementation of community planning objectives could unlock the potential for both social and economic gain at a neighbourhood level.

Moving forward, there are undoubtedly areas of growth and additional capacity required within the current spectrum of practice. The recommendations outlined in Section 6.0 
could go a long way to ease existing tensions, and benefit BIA administration and community development practice as a whole.

While these recommendations offer a great deal of opportunity for growth, uncertainty of purpose both within the BIA membership and across various government departments appears to sit at the centre of limitation. In order to advance the BIA2.0 agenda, the need for internal review and visioning is imperative. Existing BIA members need to define what they want to be, and build capacity amongst their membership to implement that role. Through more consistent action and implementation across the province, ill-founded perceptions of BIAs placement in the broader community development agenda will dissipate.

The advancement of a BIA2.0 agenda offers tremendous opportunity for the implementation of resilient and healthy communities. Leveraging the ingenuity of local business and the administrative power of municipalities, BIAs offer planning practice a unique mechanism to deliver community planning objectives from the ground up. 


\section{APPENDIX A: Organizing Business}

BIAs are a legislated local board under the Municipal Act, 2001 or City of Toronto Act, 2006. They represent a defined commercial geography within a municipality with a membership of commercial business and property owners all required to pay a municipal levy used toward property improvements, promotion and enhancement of the public realm within that local area. BIAs focus on overall improvements within their defined area in order to generate improved economic conditions, commercial activity and community assets. The levy is decided through a budgeting process with council and the rate applied on the annual property tax assessment.

A Chamber of Commerce or Business Association is also a common form of business organization in Canada. They are a voluntary group, typically made up of local business operators and key community members, focused on connecting business and creating opportunities for economic growth through the promotion and development of commercial and industrial opportunities within a larger city region. (ICC, 2015)

Municipal Services Boards are another organizational framework for business. MSBs are also established under the Municipal Act, 2001. They are considered local boards of Council and can be established by an individual municipality or by two or more municipalities. 'A municipal service board must have at least two members. Generally, former public utility commissions, parking commissions and boards of park management are now municipal service boards' (MMAH, 2015). They are required to carry out a purpose and responsibility as defined by the municipal council.

Municipal Services Corporations in contrast, are not considered to be local boards of Council. They too, are legislated under the Municipal Act, 2001, and are created by municipalities to carry out a specific service or thing on behalf of the municipality. $A$ Municipal Service Corporation has the power to own land, dispose of land, and charge user fees toward their efforts. (O.Reg.599/06, 2001).

An Economic Development Corporations (EDC) is a municipal service corporation with a specific focus on economic development activities. It functions similarly to BIAs but 
typically on a broader citywide perspective. EDCs act as a partner between a Municipality and the private sector to promote growth and expansion of local businesses and the attraction of new businesses to region. While more predominantly focused on the growth of employment and key markets as a whole, their representation of the interests of BIAs in the broader economic makeup of the City is important. 


\section{APPENDIX B: Key Informant Interview Questions}

1) How would you broadly define the mandate of a Business Improvement Area organization?

2) In practice, what types of activities have you observed BIAs undertaking? Are they consistent with the broadly defined mandate or beyond it?

3) In what ways do you think and see BIAs working on behalf of private interests?

4) In what ways to you think and see BIAs working on behalf of public interests?

5) Is there a clear structure for BIA objectives and membership across the province? How would you categorize the varying aspects of their scope of work?

6) Have you observed signals of a shift in the BIAs role in local community development? Please describe.

7) In your experience, how has the relationship between municipalities, the province and BIAs functioned? Are there areas that could be improved or supported through policy or implementation tools?

8) Are you aware of existing planning implementation tools available to BIAs to facilitate their work? Are they working in your opinion? Can you identify any existing gaps in the current planning policy framework with respect to BIA objectives?

9) How can municipal and provincial planning policy better accommodate these groups place making and local economic focus?

10)Do you see the role of the BIA in matters of public interest continuing to change and where should these organizations sit in the community planning framework? 


\section{APPENDIX C: Key Informant Interview Findings}

Interviewees were asked to broadly define the role of Business Improvement Areas and indicate what types of activities they see BIAs currently undertaking, either in line with or beyond the mandated requirements set out in the Municipal Act, 2001, and City of Toronto Act, 2006?

\section{Response:}

For the most part, interviewees felt that BIAs broadly met their responsibilities under the Municipal Act, but didn't typically often go above and beyond.

The Municipal Act defines BIA responsibilities under Section 204, to include the improvement, beautification and maintenance of municipality owned land, buildings and structures above and beyond the expense of the municipality, and to promote the area as a business or shopping district (2001, s.204). Some interviewees felt that this was a safe place for BIA operators to stay, and that to think outside the box required risk, budget, and a dynamic approach that often wasn't present.

Responses also highlighted the varying interpretations of the mandate responsibilities with some BIAs taking the Municipal Act quite literally, and others, typically with larger budgets, having some latitude to explore different aspects of promotion, marketing and advocacy. There was general agreement that there was a broad spectrum of interpretation in the industry on what the "minimum standard" requirements for a BIA are. This was assumed to be the result of resource availability, both funding and full time staff, as well as the level of experience of staff in the field.

It was noted that the City of Toronto Act, 2006 goes into more descriptive detail on BIA mandate and responsibilities, and includes policies which encourage "... strategic planning as necessary to address business improvement area issues" (2006, s.19-3f) and ".... safety and security initiatives" (2006, s.19-3e). These additional objectives set a different perceived benchmark for BIAs responsibility in the Toronto context than elsewhere in the province. 
Despite the initial response, interviewees did cite specific examples of BIAs that went above and beyond their basic responsibilities to undertake projects in Business Retention and Expansion efforts in collaboration with the municipality, help facilitate workshops related to investment in the downtown or commercial core, and assist with business recruitment activities again run out of a municipal economic development department.

Interviewees were then asked a series of questions around observed signals in a shift toward greater involvement in local community development over time. General opinion on the reasoning behind any shift, and whether or not this was considered positive or negative was also explored.

\section{Response:}

When discussing the tendency for BIAs toward broad based community development, there was an interesting distinction that arose between Toronto and the rest of Ontario.

In the Toronto context, interviewees felt that the popularity of BIAs was on the rise and place making and strategic planning efforts were cited as a common goal, particularly amongst some of the larger BIAs. Partnerships with the development community, elected officials, and academic institutions have led to a great deal of pilot programming, data mining and research, and foundational broader community planning initiatives in these districts. These were all felt to be a positive step forward for BIA programming.

In the broader Ontario context, interviewees felt that the same infrastructure for success did not exist and there was a lot of "old blood", which was making it challenging for BIAs to grow. The need for enthusiasm and consistent leadership were cited as gaps in the ability for smaller community BIAs to deliver on broad based community objectives. Those sorts of projects (strategic planning, social programming, accessibility improvements) typically require funding that the smaller BIAs can't acquire through their own levy. A community champion needs to be in place with the knowledge, partnerships and long-term employment opportunity to lead the effort. 
One interviewee felt that in order for BIAs to be able to move toward a more community focused agenda they need to be able to appeal to the non-retail small business owners/tenants within their districts. The efforts of the BIA have to serve more than just the retail member, if the project scope could be expanded than other businesses would see the value, perhaps leading to increased levy revenue.

Examples of tried and failed municipal wide BIA start ups, demonstrated very clearly that even a BIA with the best intention for broad based community development will fold without the right leadership in place and political "buy in". Both community wide BIA efforts failed as a result of an inability to prove value for the levy payment and a lack of support from the Council in power. A lesson learned in that exercise is the need for an upfront clear set of indicators for success, and beyond that, education of key players in the initiative to ensure the municipality, the public, the elected officials, and the BIA executive are aware of roles, responsibilities and outcomes.

Despite the challenges facing BIAs in delivering broad based community development initiatives, there were good news stories. The development of a weekly farmers market as a result of conscientious Business, Retention and Expansion efforts by the BIA in partnership with the township. The efforts to seek public feedback from business owners and local neighbourhood associations, despite the lack of any regulation requiring this consultation in practice. The festivals and community events held in collaboration with certain multicultural groups to celebrate a particular ethnicity that used to or currently dominates the neighbourhood landscape.

There are community development initiatives happening, but the interviewees felt the climate to enhance this work was challenging, particularly outside of Toronto.

A three-phase evolution of BIA objectives was outlined as a framework for how the industry as a whole is positioned and can shift toward greater engagement in community development. 
1) Phase 1: Establishment of a BIA. Banners go up, and small jobs are completed to demonstrate where membership levies are going.

2) Phase 2: The BIA district has been cleaned up aesthetically. Investments in building facades and streetscaping have been made. Now the focus shifts to increasing pedestrian traffic and promoting the area as a vibrant and beautiful place to spend time, and spend money. In this phase the BIA will focus their efforts on promotion, festivals, markets, community based events that will have a wider draw than the immediate community.

3) Phase 3: Is the evolution of BIA2.0 - the sophisticated BIA with a clear strategic vision on how they want to grow and a strong understanding of their retail/commercial mix in the context of the broader community. The BIA efforts in Phase 3 look to build on the commercial foundation established through phases one and two through strategic land use planning, community consultation, neighbourhood surveys and engagement and partnerships with private sector development companies and government authorities.

\section{Interviewees were asked to identify what they considered the core benefits to communities in setting up a BIA.}

\section{Response:}

Most interviewees recognized that the key benefit to a community in having a BIA is the mandatory levy, which allows for longer term planning initiatives with a stable income stream (BIA levy).

Some stated that the position of the BIA as a local board of the municipality was both a blessing and a curse. On the positive side, being a local board allows for additional municipal input into the street improvements along key commercial districts, and also gives considerable power to the BIA - to first, raise money, and second, initiate community projects. On the negative side, as a local board there is risk of deterred innovation and entrepreneurial spirit, and an inability to appeal development applications where Council is in favour. As a creature of the municipality, the BIA must fall in line with 
Council decision. This adds a level of partisan behaviour that often doesn't sit well with entrepreneurial business owners.

Others simply stated that while they anecdotally know of community development initiatives involving BIAs, they had difficulty quantifying benefit to the community without measurable indicators. The lack of consistent data on individual BIAs budgets and performance, the percentage change in the industry across the provincial landscape, and the collective agreement on data indicators adds to the general confusion on what impact BIAs are having in local community well being. Efforts are being made in the Toronto context, where the City has taken an active role in obtaining and publishing annual operational data for each of the $81 \mathrm{BIAs}$ in City. In addition to that, the province hopes to capture some information through completion of an annual Financial Information Report. That data is reliant on municipalities filling out forms correctly and communicating with OBIAA when new BIAs are formed or dissolved. Right now there is no formal requirement for a municipality to report changes in BIA status to higher authorities or OBIAA.

One interview recommended investigation into the European BIA model, where evaluation and reporting are a regular requirement of operation. The legislation in Europe emphasizes the need for BIAs to demonstrate their deliverables at the end of every Board term in order for the municipality to renew their term for another 5-years. Indicators include a Small Business Tax Revenue, pedestrian counts, safety surveys and overall ballot box opinions on cleanliness. This approach forces innovative solutions and helps to dispel uncertainty in the system on the importance of BIAs and flush out apathy in the management structure.

In smaller communities, interviewees lamented it has been a tough sell. While the funding opportunities presented to communities are likely greater with a BIA than without, in some communities there isn't a critical mass of business owners to support the BIA in election or revenues, or enough capacity at the municipality to support their growth and initiatives. 
The contextual differences between rural Ontario and larger municipalities are apparent in this discussion, as the recurring limitation to community benefit where BIAs are concerned, was the scale of the commercial precinct, the level of vacancy existing at inception, and the vested interest of the local Council in championing the cause.

At the same time, these are some of the critical areas in need of a collective voice to focus on the economic growth and social well-being. One interviewee noted that the reality in Rural Ontario is that independent businesses and mom and pop shops make up majority of business economy, where $85 \%$ of the rural commercial economy is housed in businesses with less than 10 people. This touches on a real disconnect between council Economic Development initiatives and the reality of the local economy. While it is important to create strategies to attract large scale business and industry the focus should be directed toward the incremental growth of small business. Businesses that we have are the best hope for the future. With this perspective, the successful initiation of a BIA could be an important piece in a local economic development strategy for smaller municipalities.

Further to this, interviewees were asked to identify the characteristics that make a strong BIA association and what they considered to be some of the key challenges in setting up and operating a BIA communities.

\section{Response:}

Strengths:

The qualities of a strong BIA organization were numerous and varied. Some interviewees cited their ability to form meaningful relationships and build strategic partnerships with the municipality and the Council in term. Others reference foresight, adventure, creativity and imagination as critical components of a successful organization. The number one trait of a strong BIA was the ability to communicate. The ability for a BIA to communicate effectively with the municipality, their Council, neighbourhood associations, and the public at large to build a consensus of value and lasting stakeholder relationships, will unlock the potential for community impact. 
On interviewee suggested that community groups should have representation on the BIA board. This concept has been shut down in the past on the basis that community members have no 'skin in the game', but would be a step toward best practice community development, which engaged all stakeholders. The example of ChurchWellesley BIA and their efforts with the local neighbourhood groups is case in point. When asked about BIAs relationship with local neighbourhood associations, it was not really considered to be a priority.

\section{Challenges:}

The response to this question offered a number of suggestions around the struggles faced in implementation and management of the BIA structure. Challenges in the creation of a BIA range from absentee and slum landlords who have no interest in paying an additional levy on their tax bill, to aggressive and competitive big box retailers, to vacant land and storefronts. In each instance, the animosity generated by competing and in some cases independent interests result in a BIA never taking shape. Interviewees stressed the need for a soft approach to BIA formation in its infancy - business owners need to see the value, and understand their partnership with other commercial property owners and operators prior to agreeing to its formation. These challenges are the same across all scales of settlement - neighbourhood, village, town and city, all have to deal with the competing interests of individuals to ultimately build a collective.

One of the major challenges in operation was animosity with the municipality. Interviewees stated that there is a general lack of understanding across the BIA membership of their responsibilities under the Act. Items like public meetings, appointed of staff and requirement for financial statements are all listed responsibilities of local boards under the Act, etc. As a result, perceptions among government bodies can be jaded to assume a BIA is unprofessional or incapable of the responsibilities the Act allows them to have. These perceptions permeate all activities, limiting the potential for BIA growth as a result of poor first impressions. Education and capacity building within the BIA membership was recommended to address this. 
The other major challenges include funding and staffing. These are directly linked - in that the ability to hire a full time staff member is reliant on the budget of the BIA itself. While there are funding programs in place for project work, interviewees did not have awareness of any funding for staff positions within a BIA. Outside of the levy, BIAs can access funding through a few limited grant programs, sometimes helped by the creation of a Community Improvement Plan area, but often limited by the fact that they are neither a not for profit nor an incorporated entity. The status of a BIA in the funding landscape is a proven challenge to further their efforts.

The staffing issue is considered a major hurdle for BIAs to overcome if they want to be able to implement longer-term community planning initiatives. Existing turnover rates are high, cited as a result of low wages and a somewhat precarious work environment. Old attitudes on BIA Boards often challenge the value of having a full time person on staff in a BIA, and as a worst case a climate of bullying, unpaid overtime hours and an uncertain disability coverage can often result in short term employees. If BIAs are to advance their position as local community development agents, the ability to hire full time BIA staff to represent and champion deliverables is thought to be critical. A lot of BIAs are struggling as a result of that.

Interviewees were asked to discuss the existing functional and perceived relationship of BIAs with their local municipalities. Questions regarding direct engagement in the planning framework, potential jurisdictional differences and where relationships could be improved or enhanced were explored.

\section{Response:}

All respondents agreed that a great working relationship with municipality critical to ongoing success for a BIA, but general perceptions around the capacity of a BIA to delivery broader municipal objectives vary widely. Interviewees noted that there is a lot of dysfunction in practice, and important ties with municipalities that have been severed and are difficult to repair. This uncertainty is largely as a result of inconsistent performance, lack of adherence to regulatory obligation and cited "in-fighting" between BIA Board members. Council support is paramount to furthering BIA initiatives, and many 
interviewees cited vague and open-ended communication as the biggest problem in gaining that support.

There was general agreement that BIAs functional relationship with their municipality is through the economic development department or City clerk's office. Rarely, if ever, is there a direct link to planning departments. With no legislative requirement to participate in the planning process, neither the municipality nor the BIA Board typically reach out to consult on development proposals. That said, interviewees noted that ideally secondary plans and community improvement plans in locations that encompass BIA boundaries could be done in collaboration with the BIA. While they are not land owners, the do represent the interests and practice of a defined group of land holdings. In addition, friction around the preservation and reuse of heritage properties could be abated where BIAs where involved more intimately with planning around Heritage Conservation Districts and Heritage Act applications. There was also reference to BIA hesitation in getting involved with planning matters at all, examples of Board firings as the result of opposition to planning approvals, resonate amongst BIA members. This reactive rather than proactive approach to BIA work is said to be a result of old practices hanging on in an economic and planning environment that is changing rapidly.

That said there are examples of BIAs who hold exemplary relationships with their municipal staff and elected officials. Interviewees noted these BIAs are also often the same ones delivering new initiatives to elevate the status of BIA organizations in the community development arena. Quoting best practice of some BIA members, "The board of the BIA, should always be working to have a member of council as their new best friend. Cultivating that relationship with Council so that there is a common interest. Every member of council needs to know about BIA" (personal communication, 2015).

Interviewees recommended the need to put old attitudes aside that perpetuate the "us versus them" mentality, and start building partnerships. A strong partnership with the City will ultimately lead to greater success for the BIA and the businesses within 
it. Where members of TABIA were perceived to appear confident in their municipal relationships, members of OBIAA did not appear to be the same.

\section{Interviewees were asked to discuss the existing functional and perceived relationship of BIAs with the provincial government. Questions regarding direct engagement, potential jurisdictional differences and where relationships could be improved or enhanced were explored.}

\section{Response:}

Interviewees held a fairly consistent opinion that the relationship between BIAs and the province was strong, but distant. With the province taking more of an advisory role than one that is actively engaged in practice. The timing of the change in provincial-BIA relations was thought to be as a result of the Municipal Act changes in 2001. These changes came as a result of provincial downloading to the municipalities through the late 1900s, and eventuated in the inclusion of Section 216 of the Municipal Act. Section 216 basically gave the municipalities more flexible and open-ended power to initiate and control BIA operations through by-law as they see fit.

Funding opportunities through the province were noted to have decreased over the years, with no funding potential through MMAH and increasingly limited options through OMAFRA. These shifts are consistent with fiscal restraint across all provincial ministries, and not thought to signify any commentary on BIA relevance.

On the contrary, the strength of the provincial-BIA relationship is best showcased through OBIAAs participation in the annual PERL committee meeting. PERL (Planning, Environment, Resources, Land Use) is a provincial government annual assembly of deputy ministers who meet to discuss pressing issues across their portfolios that are best served through collaboration. OBIAA has had a seat at this assembly since 2013 as a result of the Open for Business Initiative championed by then minister, now premier, Kathleen Wynne. This direct "provincial - BIA" link highlights to the importance the 
province places on small business as a component of strategic economic growth across Ontario, and in turn, OBIAAs role in facilitating that growth.

Some interviewees lamented that while certain provincial ministries see BIAs as a key client group, in other areas of the province people don't really understand the purpose, value or role that BIAs play in local economic development initiatives. The message that they do have a vital role to play in facilitating economic growth and social well-being (particularly in downtown revitalization efforts) needs to be better communicated.

Interviewees were asked to identify any policies and tools through the municipality or the province that they knew BIAs could access to implement projects. Discussion around the successes and failures of those tools was encouraged.

\section{Response:}

The majority of interviewees noted funding grants and incentives as the main implementation tool available through municipalities and the province. Funding was repeatedly cited as a major limitation on BIA best practice, and the ability to access alternative revenue streams or one off grant opportunities was critical to the longevity of BIA work. Provincial funding opportunities included the Rural Economic Development program which is geared directly toward BIAs and other economic development 'clients' of the province, Trillium Foundation grants which provide money for community development in partnership with a not-for -profit, downtown revitalization grants which offer three -year funding packages for projects geared toward downtown renewal and also include funding for staffing of the project, and various culturally based programs offered through the Ministry of Tourism, Culture and Sport. The Federal Community Futures Development Corporation (CFDC) program is focused on community projects in Eastern Ontario. This fund also requires partnership, but CFDC may be willing to bridge that gap.

Partnerships with not-for-profit organizations and municipalities were again seen as critical to unlocking the opportunities for new funding sources. Some interviewees cited 
the fact that BIAs were considered a local board of the municipality was a disadvantage when it came to accessing grants. BIAs legislative structure meant that they are neither considered a charity, not a corporation, and are often left without the ability to apply for provincial without forming external partnerships. The additional administration, lack of autonomy, and limited control over revenue, were frustrations voiced on behalf of BIAs collectively across the province. Opportunities to pool financial resources with the municipality were thought to lead to better community outcomes and place BIAS in a more prominent position in the public eye.

Beyond funding, interviewees mentioned the benefits of BIAs utilizing the provincial programming to support small business entrepreneurship in their communities. Business Retention and Expansion programs through OMAFRA were cited as catalysts for visionary local economic development approaches in smaller communities that helped to open dialogue and shift attitudes around economic opportunities in challenging contexts. The implementation of BR\&E programs was encouraged by a number of interviewees.

Finally, interviewees were asked to identify how they would suggest planning policy at a provincial and municipal level could be enhanced to encourage BIAs to engaged in community building and place making activities.

\section{Response:}

Interviewees offered the resounding message that there was no need to over regulate the system already in place. Where the Municipal Act and the City of Toronto Act are currently under review with the province, some interviewees felt that there were limited changes that could be made at this point, given the 2006 amendments that put control in the hands of municipalities.

Others suggested changes could be made to further clarify the purpose, and responsibilities of BIAs. One interviewee highlighted the key differences between the two acts, were that the City of Toronto Act allows BIAs to make physical improvements to privately owned properties, whereas the Municipal Act mandates that physical 
improvement must reside in the public realm. Perhaps these two variances should be aligned.

Noted improvements to the Municipal Act included: Clarity and expansion of the mandate to empower the business community to be community builders, consideration of expansion of BIA powers to allow the ability to own and develop property, limitations on the length of term for BIA Board members, the necessity for an agreement of understanding between Municipalities and BIAs on roles and responsibilities (termed a Memorandum of Understanding), and the addition of legislated reporting requirements between the province and municipalities to track BIA growth or decline and other critical indicators of success.

The lack of exiting accurate and quantifiable data on BIA progress and impacts in local communities has resulted in a perpetuating opinion among authorities that BIA work doesn't have considerable impact on communities, and can lead to a lack of interest and respect in their programming. Improved data capture and a defined list of indicators to measure BIA impact on the development of complete communities is noted as a critical component to elevating BIA practice. 


\section{APPENDIX D: Planning Tool Scan}

The Ministry of Municipal Housing and Affairs (MMAH) highlight the tools available to municipalities through the Planning Act to foster sustainable and investment-ready planning approaches. These are known as "Building blocks for sustainable planning," (ned). The relevant tools available to enhance and expand main street and downtown precincts are discussed below.

It should be noted that in order to offer analysis relative to the broader Ontario context, the review of locally specific documentation will be based on the general assumption of certain policy inclusions that are consistent across all municipalities. For example, when speaking to Official Plan documentation, a general acknowledgement of the provision of policies related to commercial uses, street corridors, and employment will be made.

\section{Official Plan (Planning Act s.17, 22, 26):}

At a local level, the guiding policy framework of any municipality is their Official Plan (OP). Supported by transportation, infrastructure and environmental master plans. While each Official Plan is unique to its municipality, all will typically address the goals and objectives of the broader municipality with respect to land uses and services including housing, transportation, parkland, open space, public services infrastructure, commercial, industrial, and office uses, and employment potential. As a requirement under the Planning Act, municipalities are legislated to conduct a comprehensive review and update of this plan and its supporting master plans no less than every 5 years for approval by elected Council. Each comprehensive review incorporates population and employment projections over the 20-year planning horizon and establishes a strategic plan for new capital projects within the life of the Official Plan. Within the context of Official Plans, the ability for BIAs to influence area-specific policy efforts - such as Secondary Plans, Transit Oriented Development Station Plans, and Design Guidelines must be considered. 


\section{Analysis and Advancements:}

\section{Official Plan Policy}

Policy can be a positive influence on investment in commercial districts and BIA territory. Where a municipal OP can provide policy language that both recognizes the importance of commercial main streets in building complete communities and manages the form, type, and amount of commercial development built within its boundaries, focus can be better directed toward core commercial areas.

Using the City of Toronto's Official Plan as an example of positive incentive policies, which encourage contextual and high quality development, improvements to public amenities and street infrastructure, and support for neighbourhood business associations (City of Toronto Official Plan, 2010).

Using the City of Barrie's Official Plan as an example of positive land use controls, policy 4.3.2.1 (e) notes "The City may require the proponents of any application for commercial development not provided for in this Plan and the Zoning By-law to submit detailed impact studies. Impact studies may, among other matters, include an analysis of the impact of new development on existing shopping areas, the downtown core..." (City of Barrie, 2014, 4-13). Through this policy downtown commercial activity is recognized as important to the overall vitality of the city. The mandated impact evaluation allows city staff the opportunity to assess new commercial development proposals impact on existing commercial activity.

BIAs should be aware of these types of policies in their local municipal plan in order to direct staff or Council attention to the policy commitments made to commercial mainstreets and input into any retail assessment process.

\section{Design Guidelines:}

Are aimed at providing support and guidance on the urban design elements of development in key areas of a municipality. There are typically created for major nodes and corridors, including commercial mainstreets, transit precincts and downtown areas, and offer direction on both public realm and external façade treatments. These guidelines 
are considered to be a positive control for BIA practice. They encourage improved street design and building aesthetic, which aligns exactly with the mandated responsibility of a BIA. BIAs should recognize the importance of input into these documents as they shape the design of street elements that BIA members rely on to encourage business and invest in through their levy payments. As "guardians of the local commercial street," municipalities could work more with BIAs in the creation of these guidelines to reflect contextual local knowledge.

\section{Development Applications}

Development applications including site plan control (s.41), plan of subdivision (s.51), and minor variance (s.34) propose plans for the development or redevelopment of a site specific project based on the policies of the higher order policy documents. The processing of these applications with the municipality is governed under the Act, and guided by the policies of the Official Plan. Formal public consultation requirements and processes vary dependent on the application. The opportunity for BIAs to become aware of these applications and provide comment is imperative to both the public and private sector understanding neighbourhood scale growth.

\section{Analysis and Advancements:}

The development application process is considered to be a positive control for BIAs in that they create an opportunity for more refined study of a particular issue, site or area that a BIA is either a part of or could benefit from future development. That said, there are limitations within the current process that should be recognized and improved upon. Namely processing time, commercial analysis, and consultation.

With respect to time, processing times on development applications are typically lengthy. This administrative bottleneck, while necessary to ensure appropriate land use development and protection, can often limit innovation and business entrepreneurship. In some respects, planning regulation gets in the way of the policies it hopes to implement. The intrinsic value of spontaneity and creativity that is so often found in neighbourhood entrepreneurship must be recognized and supported as an important driver of economic growth at a local level. Where necessary planning processes can be streamlined to 
maintain the organic and often innovative growth of neighbourhood small business and community well being that should be encouraged. Collaboration between the BIA and the municipality on the challenges of lengthy application timelines could effectively advance this streamlining. With respect to public consultation, each development application has varying requirements for public consultation under the act. While regularly encouraged by municipal staff and often undertaken by development proponents, the requirement for consultation remains varied.

Minor variance consultation is not mandated until the public hearing date. Site Plan Control applications can be to be approved under delegated authority by municipal staff, and have no mandatory public meeting requirement if within an approved Plan of Subdivision. Plan of Subdivision applications themselves, which do require public consultation prior to approval, can also often be approved under delegated authority. While the streamlining of development processes is encouraged and important for commercial activity and growth, the varying levels of required consultation can result in confusion and missed opportunities. Without active monitoring of Committee agendas, BIAs may not be informed of proposed changes along the mainstreet that could implicate both the levy payments and future community development activity within their jurisdiction.

As a local board of the municipality, one suggestion is for BIAs to be circulated on all applications within their defined boundaries to ensure the opportunity to participate and comment. Another suggestion is for all site plan and plan of subdivision approvals issued within a defined BIA boundary, a clearing condition be added requiring clearance by the BIA prior to registration. This would ensure that the delivery of new development within important economic precincts of communities remains aligned with the needs of the commercial precinct.

It is also worth noting that the submission requirements listed under the Act leave discretion to the municipalities on the need for a retail commercial analysis as part of a development application submission. Where a development proposal impacts a defined BIA precinct, commercial analysis should be undertaken to plan for the implementation of 
proposed land uses and deliver on the vision for complete communities with access to appropriate services. This requirement could be requested prior to approval by the municipality, or where not required, listed as a condition of clearance for the elected BIA Board to approve prior to registration.

\section{Height and Density Bonusing (Planning Act, s.37):}

Section 37 of the Planning Act allows municipalities to authorize permission for additional height or density on a particular site in exchange for community benefit. The agreement is enacted by By-Law, and the increased development rights must comply with the policies of the Official Plan before approval. Community benefits are then determined through a negotiation between the landowner (applicant), the municipality, and the elected official of that ward.

\section{Analysis and Advancements:}

Section 37 density bonusing payments are considered to be a positive incentive to BIA practice. The challenge for BIAs is finding the opportunity to access and utilize those funds. As the value and allocation of Section 37 funds is decided in closed door consultation the locally elected councillor, BIAs have the opportunity to leverage their relationship with the local councillor (who may be a BIA Board member) to access those funds as an additional revenue stream. Much of the criticism around Section 37 contributions in the Toronto context has been the lack of clarity, transparency and realizable benefit that has come from the current process.

Operating in the public interest, BIAs should have the opportunity to assist in the creation of a suitable list of local community benefits. Working with the municipality and elected councillor, this involvement would assist in furthering the economic growth and social well-being of places. BIAs should also be encouraged to take a proactive project management role to deliver the measurable benefits of Section 37 funds to their community. This project management role would be a new and space for BIAs within the municipality, and help to facilitate on the ground tangible benefits to local communities. 
For example, the implementation guidelines and negotiation protocol for Section 37 benefit agreements in the Toronto context were adopted in 2007 (City of Toronto, n.d), and inform the policies around Section 37 found in the Official Plan.

\section{Development Permit System (Planning Act, s.70.2 and O.Reg.608/06)}

The Development Permit System (DPS) is a tool available to municipalities under the Planning Act to integrate precinct planning and the needed development approvals including site plan control, zoning by-law amendment, and minor variance into one single application. It is a streamlining tool currently utilized in the City of Toronto, with limited take up in other jurisdictions across the province to date.

\section{Bill 73 - Smart Growth for Communities Act:}

Introduced in March 2015, Bill 73 was introduced with proposed amendments to both the Planning Act and the Development Charges Act in the interest of increased community consultation and transparency. Proposed changes include a two-year moratorium on Official Plan amendments and minor variance application following adoption of a plan, consultation and a re-definition of the definition of minor variances, and increased consultation requirements for all development applications. The Bill also outlines a refined process for development contributions under Section 37 and Section 42, which improved transparency and requires annual reporting by the municipality. The public comment period closed in June 2015, and stakeholder-working groups are currently underway (Toronto, 2015, slides 1-7). 


\section{REFERENCES}

Canadian Urban Institute (2013), The Value of Investing in Canadian Downtowns prepared for the Canadian Issues Task Force of the International Downtown Association, 1-102.

City of Barrie Official Plan (2014), City of Barrie Official Plan, Section 4-13, policy 4.3.2.1(e).

City of Burlington (May 2012) Burlington Downtown Benchmarking and Best Practices Report, prepared by Amanda Gubbels, 1-158.

City of London (n.d) City of London Zoning By-Law, Z-1 Section 20 - Downtown Zone, policy 20.1. Retrieved From: http://apps.london.ca/by-laws/chaptr20.htm

City of Toronto (n.d) Strategic Initiatives, Policy and Analysis: Section 37 Benefits, Retrieved from:

http://www1.toronto.ca/wps/portal/contentonly?vgnextoid=7e570621f3161410VgnVCM100 00071d60f89RCRD\&vgnextchannel=8e6552cc66061410VgnVCM10000071d60f89RCRD

City of Toronto (December, 2013) City of Toronto Act 2006, Municipal Code: Chapter 19 Business Improvement Areas: Retrieved From:

http://www.toronto.ca/legdocs/municode/1184_019.pdf

City of Ottawa (2009), City of Ottawa Official Plan, Volume 2A - Richmond Westboro Secondary Plan, Policy 1.3.4. Sector 5 (e), p. 6).

Collingwood Business Improvement Area Association (2015), 2015 BIA Achievement Awards Nomination, Mainstreet Accessibility Award - BIA presentation slides, slides 1-16.

Community Economic Development - Building for Social Change By: Eric Shragge and Michael Toye (eds.)

County of Bruce (n.d.), County of Bruce Homepage, Spuce the Bruce, All Spruced Up! Retreived from: http://www.brucecounty.on.ca/business/spruce-the-bruce/before-andafter.php

Erzberger, C. and Kelle, U. (2003) 'Making inferences in mixed methods: the rules of integration', found in Bergman, M. (2008) Advances in Mixed Methods Research, Sage journals, 22-37.

Food and Agriculture Association of the United Nations (n.d.) Environmental Impact Assessment and Environmental Auditing (EA), section 2.6.2 Retrieved from: http://www.fao.org/docrep/005/v9933e/v9933e02.htm 
Green, Ilja. (2012). To BIA or not BIA...? Published by McGill University Press, 1-48.

Gomez, R. Isakov, A., Semasky, M. (2015). Small Business and the City: The Transformative Potential of small scale entrepreneurship. Rotman-UTP Publishing, 1-312.

Ha, Steve (2011) An Economic Benefit Study to Establish an Asheville Downtown Business Improvement District, published for the City of Asheville, page iv.

Hodge,G., Gordon, D. (2008) Planning Canadian Communities, 5th Edition, 376.

Hoetjes, P.J. (2010) Mapping the Market: A portfolio approach for informed urban development strategies, Amsterdam Institute of Social Sciences Research, downloaded from UvA-DARE publication 73749, 41-48.

Hoyt, Lorlene (2001). Untold Stories and Substantiated Impacts, published by the University of Pennslyvania, 1-30.

International Chamber of Commerce website (2015) The Merchants of Peace, Retrieved from: http://www.iccwbo.org/about-icc/history/

International Downtown Association (2011) U.S. BID Census Report, 1-46.

Isakov, Andre. (2009). Business Improvement Areas in British Columbia. Published by Simon Fraser University, 1-85.

London LAWN (n.d.) London LAWN homepage, FAQ's, retrieved from: http://www.londonlawn.ca/

Lucas, Jack (2013) Hidden in Plain View: Local Agencies, Boards and Commissions in Canada, published in IMFG Perspectives, no.4/2013, 1-11.

Ministry of Economic Development, Employment and Infrastructure (2015), Ontario Open for Business, Open for Business Roundtable: Business Improvement Areas, 1-17.

Ministry of Municipal Affairs and Housing (2015) Municipal Councillors Guide, Section 2: An Overview of Local Government. Retrieved from: http://www.mah.gov.on.ca/Page8391.aspx

Ministry of Municipal Affairs and Housing (2001) O.Reg 599/06, policies 3 and 9.Ontario Business Improvement Area Association (2015), 2015 BIA Awards "Call for Awards Submissions", 1-4. 
Ministry of Municipal Affairs and Housing (2009), Infosheet: Planning for community design, produced by Provincial Planning Policy Branch, 1-4.

Ministry of Municipal Affairs and Housing (2009), Infosheet: Planning for intensification, produced by Provincial Planning Policy Branch, 1-4.

Ministry of Municipal Housing and Affairs (2010) Business Improvement Area Handbook, 1121.

Ontario Business Improvement Area Association (2009), Business Improvement Association Awards presented by OBIAA and TABIA, 1-8.

Ontario Business Improvement Area Association (n.d) Website home page. Retrieved from: http://obiaa.com/

Parkinson, L., Roseland, M. (2002) Leaders of the Pack: An evaluation of the Federation of Canadian Municipalities Sustainable Communities Initiative, 1-21.

Ponce, Leopold (n.d.) The Leopold Matrix for evaluating environmental impact. Retrieved from: http://ponce.sdsu.edu/the_leopold_matrix.html

Province of Ontario (2001) Province of Ontario eLaws, Municipal Act 2001, O.Reg 599/06. Retrieved from: http://www.ontario.ca/laws/regulation/060599\#BK2

Province of Ontario (2014) Provincial Policy Statement published by the Ministry of Municipal Affairs and Housing, 1-56.

Province of Ontario (January, 2015) Province of Ontario eLaws, Municipal Act 2001, S.O.2001, c.25: Sections 204-216. Retrieved from:

http://www.ontario.ca/laws/statute/01m25 - top

Roseland, Mark (1997) Dimensions of the eco-city, article in CITIES, August 1997, 1-7.

Roseland, Mark (2000) Sustainable community development: integrating environmental, economic, and social objectives published in Progress in Planning (2000), 73-132.

Rotman School of Management, University of Toronto (2015), Big Cities, Big Ideas @Rotman Speaker Series: Small Business and the City, held May 25, 2015.

St.Thomas Business Improvement Area (2015) Nostalgia Nights: A unique carshow in downtown St. Thomas BIA achievement awards presentation, slides 1-9. 
Statistics Canada (n.d), Census Profiles, Retrieved from: http://www12.statcan.gc.ca/censusrecensement/2011/dp-pd/prof/index.cfm?Lang=E

Swinburn, G., Goga, S., Murphy, F.(2006), Local Economic Development: A Primer Developing and Implementing Local Economic Development Strategies and Action Plans. Retrieved from: http://go.worldbank.org/EA784ZB3F0

Toronto Financial District BIA (2015). @ MyTOFD Award Submission: Building Community in the Towers and Tunnels presentation, slides 1-12.

Toronto Financial District BIA (2015). Raising the Standard - A Public Realm Strategy for Toronto's Financial District presentation, slides 1-12.

Town of Collingwood (n.d), Website Collingwood Downtown. Retrieved from: http://www.collingwood.ca/collingwood-downtown

Township of Huron East (2015) Huron Economic Development Partnership - CED Fund Applicant Final Report, 1-5.

TV Ontario (April 23, 2015) The Agenda with Steve Paikin: Small Business, Big Impact. Retrieved from: http://tvo.org/video/212359/small-business-big-impact

UN-Habitat (2014) Discussion Note 3: Urban Planning a new strategy of sustainable neighbourhood planning: Five Principles, 1-8. 